\title{
O Stock Serra da Acauã: um exemplo de granito tipo I fracionado oxidado no Domínio Rio Piranhas-Seridó, NE do Brasil
}

\author{
The Serra da Acauã Stock: an example of oxidized fractionated \\ type I granite in the Piranhas-Seridó River Domain (PSD), NE of Brazil \\ Mateus de Araújo Silva ${ }^{1}$ (D), Antonio Carlos Galindo ${ }^{1}$ (D), \\ Raquel Franco de Souza ${ }^{1}$ (D), Rogério Cavalcante ${ }^{2}$ (D), Vladimir Cruz de Medeiros ${ }^{2}$ (i) \\ ${ }^{1}$ Universidade Federal do Rio Grande do Norte - UFRN, Centro de Ciências Exatas e da Terra, Programa de Pós-Graduação \\ em Geodinâmica e Geofísica - CCET/PPGG, Campus Universitário, 3.000, Lagoa Nova, Caixa Postal 1.500, CEP 59078-970, \\ Natal, RN, BR (dearaujosilvamateus@gmail.com; galindo@geologia.ufrn.br; raquel@geologia.ufrn.br) \\ ${ }^{2}$ Companhia de Pesquisa e Recursos Minerais - CPRM (Serviço Geológico do Brasil), Natal, RN, BR \\ (rogerio.cavalcante@cprm.gov.br; vladimir.medeiros@cprm.gov.br)
}

Recebido em 19 de junho de 2018; aceito 31 de maio de 2019

\begin{abstract}
Resumo
O Stock Serra da Acauã está inserido no contexto da atividade plutônica ediacarana, uma das mais importantes feições geológicas na Província Borborema, Nordeste do Brasil. O corpo está dividido em duas fácies: uma equigranular fina a média e outra inequigranular média a fracamente porfirítica com fenocristais de K-feldspato. Determinações U-Pb em zircão apontaram uma idade ediacarana de c.a 578 Ma para a sua cristalização. Petrograficamente, o stock consiste de um biotita monzogranitos hololeucocráticos a leucocráticos $(\mathrm{M}=1,3-9,9 \%)$, com biotita sendo o máfico principal $(0,5$ a $8,1 \%)$. Minerais opacos, titanita, allanita, apatita e zircão são acessórios e as fases minerais mais precoces. As rochas que formam o stock são geoquimicamente similares, de caráter fracamente peraluminoso $(1,00 \leq \mathrm{A} / \mathrm{CNK} \leq 1,04)$, com coríndon normativo e de assinatura transicional entre rochas alcalinas e calcioalcalinas. A variação do conteúdo de óxidos e elementos traço sugere o fracionamento de plagioclásio, biotita, titanita, apatita e magnetita durante a cristalização do magma. O diagrama para elementos terras raras mostra enriquecimento dos elementos terras raras leves em relação aos elementos terras raras pesados, com razões $\mathrm{La}_{N} / \mathrm{Yb}_{N}$ entre 16,10 e 54,75, e anomalias negativas de $\mathrm{Eu}\left(\mathrm{Eu} / \mathrm{Eu}^{*}\right.$ de 0,66 a 0,90) compatíveis com fracionamento de plagioclásio. Dados referentes à temperatura de saturação de zircão somados a diagramas discriminantes geoquímicos permitem associar essas rochas a granitos tipo I altamente fracionados. O conjunto de dados permite correlacionar o magmatismo no contexto de granitoides calcioalcalinos de alto potássio, tardi a pós-tectônicos do Domínio Rio Piranhas-Seridó.
\end{abstract}

Palavras-chave: Plutonismo ediacarano; Domínio Rio Piranhas-Seridó; Stock Serra da Acauã; Petrologia.

\begin{abstract}
The Serra da Acauã Stock is inserted in the context of Ediacaran plutonic activity, one of the most important geological features of the Borborema Province, NE of Brazil. The body is divided into two facies: one fine to medium equigranular and other medium to weakly porphyritic unequigranular with K-feldspar phenocrysts. U-Pb determinations in zircon indicated an ediacaran age of c. $578 \mathrm{Ma}$ for its crystallization. Petrographically, the stock consists of hololeucocratic to leucocratic biotite-monzogranites $(\mathrm{M}=1.3 \%-9.9 \%)$, with biotite being the main mafic $(0.5$ to $8.1 \%)$. Opaque minerals, titanite, allanite, apatite and zircon are accessories and the earliest mineral phases. Geochemically, the rocks that form the stock are similar, with a weakly peraluminous character $(1.00 \leq \mathrm{A} / \mathrm{CNK} \leq 1.04)$, with normative corundum and transition signature between alkaline and calc-alkaline rocks. The variation of the amount of oxides and trace elements suggests the fractionation of plagioclase, biotite, titanite, apatite and magnetite during crystallization of magma. The diagram for the rare earth element (REE) groups shows the enrichment of the LREE relative to the HREE, with the LaN/YbN ratios between 16.10 and 54.75 , and negative anomalies of $\mathrm{Eu}\left(\mathrm{Eu} / \mathrm{Eu}^{*}\right.$ of 0.66 to 0.90$)$ compatible with plagioclase fractionation. Data related to the temperature of zircon saturation added to geochemical discriminant diagrams have the potential to associate these rocks to a highly fragmented type I granites. The data set allows correlating the magmatism in the context of high-K calc-alkaline granites, late to post-tectonics of Piranhas-Seridó River Domain.
\end{abstract}

Keywords: Ediacaran plutonism; Rio Piranhas-Seridó Domain; Serra da Acauã Stock; Petrology. 


\section{INTRODUÇÃO}

Um abundante magmatismo plutônico ediacarano, juntamente com uma intensa trama de zonas de cisalhamento (na sua grande maioria com transcorrências de cinemática dextral) são considerados as mais importantes feições geológicas da Província Borborema (PB) (Almeida et al., 1981), Nordeste do Brasil. No Domínio Rio Piranhas-Seridó (DPS), extremo nordeste da referida província, esse magmatismo é representado por uma série de corpos/plutões sin a pós-orogênicos compondo batólitos, stocks e diques, contexto no qual se insere o Stock Serra da Acauã (SSA). Embora existam notáveis contribuições nos últimos anos relacionadas a tal magmatismo (Nascimento et al., 2015; Macêdo Filho e Souza, 2016; Campos et al., 2016; Silva, 2016; Souza et al., 2016; Souza et al., 2017), alguns corpos necessitam de estudos petrológicos e geoquímicos mais detalhados. O estudo integrado do SSA (geologia, petrografia, geocronologia e geoquímica) pode trazer informações importantes para uma melhor compreensão/discussão acerca do magmatismo granítico ediacarano no contexto do DPS.

\section{GEOLOGIA REGIONAL}

Diversos modelos de compartimentação tectônica foram elaborados para a PB, definida por Almeida et al. (1981), Jardim de Sá (1994), Santos (1995, 1999), Van Schmus et al. (1997), Bizzi et al. (2003), Delgado et al. (2003) e Medeiros et al. (2017). Nos trabalhos citados, os autores tomaram por base tanto a subdivisão da PB em faixas dobradas/supracrustais como em maciços medianos, ou em domínios estruturais.

Angelim et al. (2006) definiram o DPS na porção setentrional da PB (Figura 1). Esse domínio é composto de um

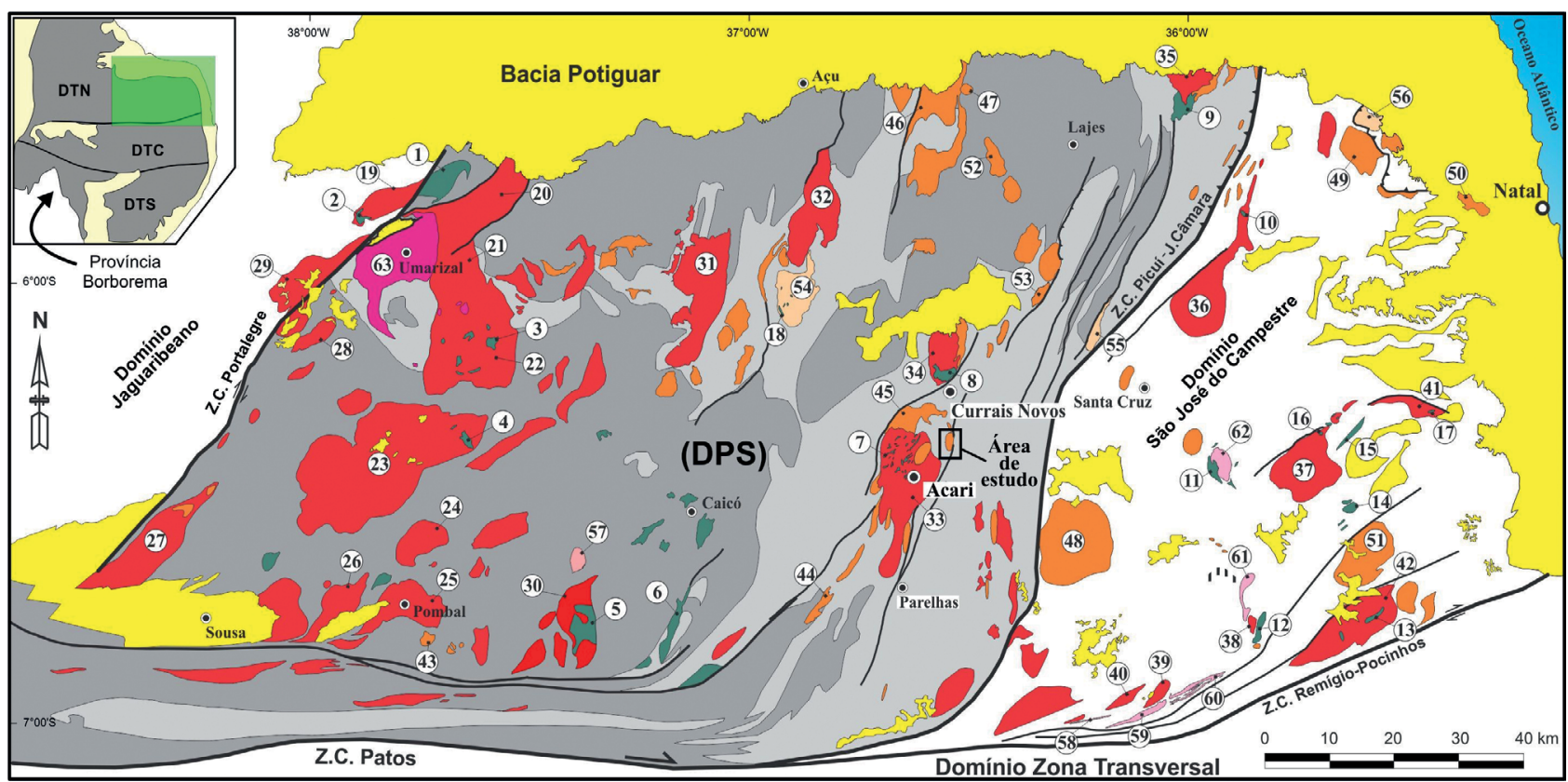

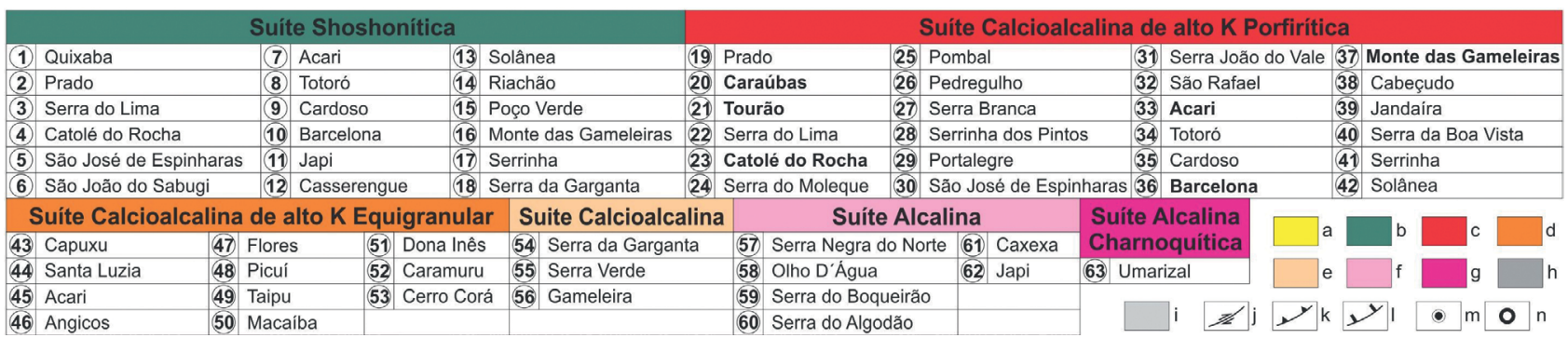

DTN: Domínio Tectônico Norte; DTC: Domínio Tectônico Central; DTS: Domínio Tectônico Sul; DPS: Domínio Rio Piranhas-Seridó; a: coberturas mesocenozoicas; b: Suíte Shoshonítica; c: Suíte Cálcio alcalina de alto K porfirítica; d: Suíte Cálcioalcalina de alto K equigranular; e: Suíte Cálcio-alcalina; f: Suíte Alcalina; g: Suíte Alcalina Charnoquítica; h: Embasamento gnaissicomigmatítico paleoproterozoico; i: Grupo Seridó; j: zonas de cisalhamento transcorrentes neoproterozoicas; k: zonas de cisalhamento contracionais-transpressivas neoproterozoicas; l: zonas de cisalhamento extensionais neoproterozoicas; m: cidades; n: capital do estado. Fonte: modificado de Nascimento et al. (2015).

Figura 1. Arcabouço geológico do Domínio Rio Piranhas-Seridó, com ênfase no magmatismo ediacarano a cambriano. 
embasamento gnáissico-migmatítico, com rochas riacianas (Complexo Caicó e Suíte Poço da Cruz) e por algumas ocorrências de idades neoarqueanas (Cavalcante et al., 2018) e estaterianas (Hollanda et al., 2011; Medeiros et al., 2012; Costa et al., 2015; Medeiros et al., 2017). Sobre elas repousa um conjunto de rochas supracrustais, de natureza metavulcanossedimentar de idade neoproterozoica, o chamado Grupo Seridó. Intrudindo as unidades supracitadas há dezenas de batólitos, stocks e diques associados a um intenso plutonismo granítitco brasiliano/panafricano, a exemplo do próprio SSA.

O Complexo Caicó é composto predominantemente por sequências de rochas metaplutônicas (ortognaisses migmatizados graníticos a dioríticos, com quimismo calcioalcalinoalcalino de alto K, e anfibolitos) e metavulcanossedimentares (mármores, quartzitos, kinzigitos e gnaisses calcissilicáticos), cortadas por augen gnaisses e diques máficos a ultramáficos (anfibolito e hornblendito), incluindo metaleucogabros (Jardim de Sá et al., 1988; Hackspacher et al., 1990; Souza et al., 1993, 2007, 2016; Hollanda et al., 2011). Por sua vez, a suíte Poço da Cruz (Ferreira et al., 1998) engloba principalmente augen ortognaisses de natureza quartzo monzonítica a granítica, de textura grossa a muito grossa, de afinidade geoquímica com granitoides calcioalcalinos de alto $\mathrm{K}$.

Dados de U-Pb em zircão obtidos por Archanjo e Hollanda (2015) revelaram idades de cristalização de $2227 \pm 5 \mathrm{Ma}$ para as metaplutônicas/ortognaisses migmatizados, e de $2184 \pm 16$ Ma e $2189 \pm 11$ Ma para os augen gnaisses do Complexo Caicó. Esses autores ainda sugeriram idades U-Pb de $1750 \pm 12$ Ma para a cristalização dos augen gnaisses grossos da região sul de Serra Negra (Rio Grande do Norte), indicando, por sua vez, um prolongamento da atividade magmática para o Estateriano. Essas idades estão em conformidade com aquelas obtidas em trabalhos anteriores (Legrand et al., 1991; Dantas, 1992; Hollanda et al., 2011; Medeiros et al., 2012).

Segundo Jardim de Sá (1994), o Grupo Seridó está dividido em três unidades litoestratigráficas, sendo elas, da base para o topo: Formação Jucurutu, Formação Equador e Formação Seridó. $\mathrm{O}$ autor supracitado as considerou como parte de um mesmo megaciclo de sedimentação, sem discordâncias regionais intervenientes.

Trabalhos de datação de Van Schmus et al. (2003) e Hollanda et al. (2015), pelo método U-Pb em zircões detríticos nas Formações Jucurutu e Seridó, revelaram idades mínimas de $634 \pm 13$ Ma e $628 \pm 16 \mathrm{Ma}$, respectivamente, sinalizando uma idade ediacarana para a sedimentação dessas sequências. Aqueles autores concluíram que um curto ciclo tectônico extensional e contracional entre 700 e $600 \mathrm{Ma}$ pode ter originado a bacia e sua subsequente deformação.

Várias tentativas de classificação foram propostas para o plutonismo brasiliano na $\mathrm{PB}$ com base em parâmetros tectônicos, petrográficos e químicos (Almeida et al., 1967;
Sial, 1987; Ferreira et al., 1998), além de algumas mais inerentes aos granitoides dentro do DPS (Jardim de Sá et al., 1981; Jardim de Sá, 1994; Nascimento et al., 2000, 2008, 2015; Angelim et al., 2006).

Nascimento et al. (2015) agruparam os granitoides do DPS em seis diferentes suítes: shoshonítica (grabros, dioritos a quartzo monzonitos), calcioalcalina de alto $\mathrm{K}$ porfirítica (predominam monzogranitos com fenocristais de $\mathrm{K}$-feldspato), calcioalcalina de alto $\mathrm{K}$ equigranular (monzogranitos equigranulares ou microporfiríticos), calcioalcalina (granodioritos a tonalitos inequigranulares, médios a grossos), alcalina (composta por alcalifeldspato granito com quartzo alcalifeldspato sienito e sienogranitos subordinados) e alcalina charnoquítica (quartzo mangeritos a charnoquitos, de granulação média a grossa e inequigranulares) (Figura 1).

Esses mesmos autores mostram um resumo de dados geocronológicos onde as idades U-Pb dos granitoides no Domínio Rio Grande do Norte variam entre 628 e $541 \mathrm{Ma}$, sem aparente zoneamento temporal entre as diferentes suítes apresentadas pelos referidos autores. Mais recentemente, Hollanda et al. (2017) obtiveram idades U-Pb em biotita leucogranitos do DPS variando entre $575 \pm 10$ Ma e $527 \pm 8$ Ma. Os autores supracitados afirmam que o período final da atividade magmática félsica ocorreu aproximadamente entre 550 e $525 \mathrm{Ma}$, com as últimas intrusões sobrepondo-se em tempo e espaço à colocação de pegmatitos mineralizados em Ta e Li na PB.

\section{MATERIAIS E MÉTODOS}

Foram coletadas duas amostras para datação, uma da fácies equigranular fina a média (RC-1176a) e outra, a RC-1177a, da fácies inequigranular média a fracamente porfirítica. Elas foram submetidas às técnicas padrões de preparação, iniciando pela cominuição (britagem e moagem). Posteriormente foi feita separação na bateia dos minerais mais densos; os minerais pesados não magnéticos foram então separados no separador Frantz e os zircões foram decantados utilizando líquidos densos, etapas realizadas na Universidade Federal do Rio Grande do Norte (UFRN). Em seguida, o material foi enviado ao Centro de Pesquisas Geocronológicas da Universidade de São Paulo (CPGeo/USP) para datação.

Os zircões selecionados foram fotografados por catodoluminescência usando um detector CEN-TAURUS ${ }^{\oplus}$ com um intervalo dinâmico de comprimento de onda de 185 a $850 \mathrm{~nm}$ acoplado a um microscópio eletrônico de varredura (MEV) FEI Quanta 250, operando a $15 \mathrm{kV}$ EHT e a uma distância de trabalho de $17 \mathrm{~mm}$. Após o imageamento, as composições isotópicas de $\mathrm{U}-\mathrm{Th}-\mathrm{Pb}$ foram determinadas utilizando a técnica de microssonda iônica de alta resolução e de alta sensibilidade (sensitive high resolution ion micro 
probe - SHRIMP IIe/MC) do CPGeo/USP, obedecendo ao procedimento analítico proposto por Sato et al. (2014).

Para a caracterização petrográfica das rochas do SSA, foram descritas dez seções delgadas (cinco de cada fácies). A nomenclatura e a classificação adotadas atendem à proposta de Streckeisen (1976). O microscópio utilizado no estudo foi o modelo BX51, da Olympus. Para o cálculo da composição modal foram contados mil pontos por seção, com o uso do software Hardledge, versão 1.6.5.1111, da Endeeper $^{\circledast}$. $\mathrm{O}$ teor de anortita dos plagioclásios foi determinado pela aplicação do método óptico de Michel-Lévy. Os minerais opacos foram estudados tanto ao microscópio óptico em luz refletida quanto em MEV. Para tal, foram confeccionadas duas seções polidas, sendo uma para cada fácies. A primeira etapa do polimento se processou com o uso de pós de carbeto de silício (1.500, 2.000 e 3.000 mesh $)$ e água destilada, sobre uma base de vidro. A segunda etapa se deu por meio do uso de panos de polimento combinados com pasta diamantada $(3,1$ e $1 / 4 \mu \mathrm{m})$ e lubrificante a base de álcool (DP-Lubricant Blue), ambos da Struers, respeitando-se um tempo médio (fases) de polimento de 30 minutos para cada granulometria utilizada. Entre cada uma dessas fases, as amostras foram lavadas com água e detergente líquido, submetidas a banho por ultrassom, para remoção de eventuais partículas não removidas na limpeza comum, e seguiram para o dessecador para retirada de umidade $\mathrm{e}$ inibição da oxidação do material.

As análises das seções polidas no MEV foram feitas com um modelo TM3000, da Hitachi, acoplado ao sistema de microanálise Energy Dispersive X-Ray Spectrometer (EDS), modelo Quantax70 da Bruker, operando a uma tensão de aceleração de $15 \mathrm{k}$ e respeitando um tempo médio de análise por ponto de $60 \mathrm{~s}$. Essa etapa se desenvolveu nas dependências do Laboratório de Caracterização Estrutural de Materiais da UFRN, permitindo, assim, uma análise semiquantitativa do conteúdo de minerais opacos, bem como a obtenção de mapas elementais e de imagens de elétrons retroespalhados (backscattered electrons).

Os dados geoquímicos são provenientes de um conjunto total de dez amostras, sendo seis da fácies inequigranular média a fracamente porfirítica (IMFP), dominante no stock, e quatro da fácies equigranular fina a média (EFM), subordinada. A preparação das amostras e a obtenção dos dados analíticos de elementos maiores, traço e terras raras ficaram a cargo da SGS Geosol - Laboratórios LTDA. As análises dos elementos maiores e menores foram obtidas em rocha total por fluorescência de raios $X$ (FRX) em pastilhas fundidas com tetraborato de lítio, enquanto elementos traços e terras raras foram determinados por espectrometria de massa com plasma indutivamente acoplado (ICP-MS), após fusão com metaborato de lítio. A perda ao fogo foi calculada pela diferença de peso após aquecer $0,2 \mathrm{~g}$ de amostra a $1.000^{\circ} \mathrm{C}$. O erro analítico é menor do que $2 \%$ para os óxidos e $5 \%$ para os elementos traços.

\section{RESULTADOS}

\section{Contexto geológico do Stock Serra da Acauã}

O SSA abrange uma área aflorante em torno de $7 \mathrm{~km}^{2}$, situado na divisa entre os municípios de Currais Novos e Acari, ambos no estado do Rio Grande do Norte. Geologicamente, situa-se na porção leste do DPS. O stock compreende alguns serrotes, os quais oscilam entre 350 e $590 \mathrm{~m}$ de altitude, separados por vales, destacando-se, entre eles, a Serra da Acauã, mais a norte.

Cartograficamente o SSA é representado por duas fácies graníticas de coloração cinza clara a levemente rosadas, leucocráticas, com biotita sendo o principal máfico. Essas fácies são texturalmente distintas: uma é IMFP, dominante em cerca de $80 \%$ do stock, e outra é EFM, subordinada, $\pm 20 \%$ (Figuras 2, 3A e 3B).

O SSA ocorre intrusivo em granada-biotita xistos ( \pm cordierita) lepidonematoporfiroblásticos da Formação Seridó, a qual apresenta uma direção de foliação principal $\left(\mathrm{S}_{\mathrm{p} 3}\right) \mathrm{NNE}-\mathrm{SSW}$ de mergulho forte a subvertical, sobretudo nas proximidades das zonas de cisalhamento transcorrentes Gargalheiras e Currais Novos, ambas de cinemática dextral. A colocação do SSA nessa unidade se dá sob caráter tardicinemático, entre as zonas de cisalhamento supracitadas.

Evidenciam-se as estruturas de fluxo magmático do stock pela orientação preferencial (NNE-SSW) dos fenocristais de $\mathrm{K}$-feldspatos ( 2 a $4 \mathrm{~cm}$ ao longo do seu eixo de alongamento) e, ocasionalmente, pela orientação de enclaves centimétricos dioríticos/quartzo-dioríticos do tipo mafic microgranular enclaves (MME), distribuídos indistintamente nas duas fácies, os quais mostram texturas tipos mingling e mixing com os biotita monzogranitos (Figura 3C).

O SSA é dominado por um regime deformacional de caráter rúptil. Além das falhas transcorrentes sinistrais mencionadas, são observados pares conjugados e feixes de fraturas N-S e E-W, bem como diques de pegmatitos e aplitos, também E-W, e ainda veios de quartzo (Figura 3D).

\section{Geocronologia}

De modo geral, os cristais de zircões analisados são euédricos, de hábito prismático, com comprimentos sempre inferiores a $400 \mu \mathrm{m}$, fortemente zonados e com poucas fraturas e ausência de núcleos herdados e bordas de recristalização. A morfologia dos cristais associada a razões $\mathrm{Th} / \mathrm{U}$ variando de 0,34 a 2,22 indicam uma origem ígnea para os zircões estudados, obedecendo à proposta de Lopez-Sanchez et al. (2016). Os resultados das análises de 8 zircões do fácies EFM e de 11 zircões do fácies IMFP são apresentados na Tabela 1. Tais análises forneceram as idades concórdia de $579 \pm 3$ Ma (MSWD de 1,7) para a fácies EFM e $577 \pm 3$ Ma para a fácies IMFP(Medeiros et al., 2017), definindo uma idade média de c.a 578 Ma, interpretada como idade de cristalização do granito (Figuras 4A e 4B). 


\section{Petrografia}

Petrograficamente, as duas fácies do SSA são semelhantes. Ambas correspondem à biotita monzogranitos hololeucocráticos a leucocráticos ( $\mathrm{M}=1,3$ a 9,9\%) (Figura 5). Quartzo, microclina e plagioclásio constituem a paragênese félsica e dominante.
Biotita é o máfico principal (entre 0,5 e 8,1\%). Minerais opacos, titanita, allanita, apatita e zircão são traços (sempre $\leq 1,5 \%$ ) e aparecem como as fases minerais mais precoces. Clorita, mica branca e carbonato são fases tardias, produtos de alteração hidrotermal de estágio subsolidus de biotita e feldspatos. Os dados das composições modais são apresentados na Tabela 2.

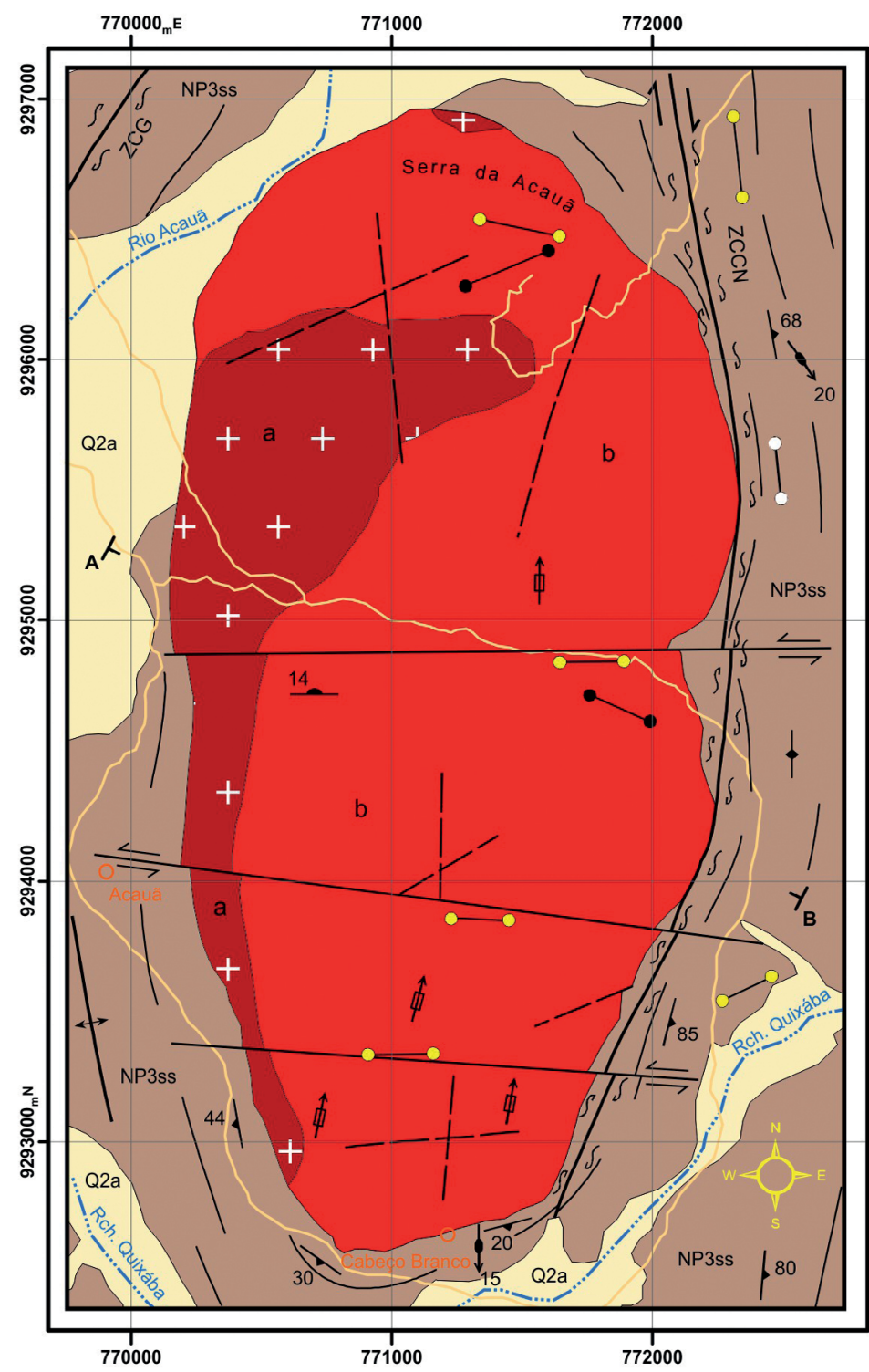

\section{을 Cenozoico \\ Q2a Depósitos aluvionares: areias, cascalhos e argilas.}

\section{Neoproterozoico}

Stock Serra da Acauã (SSA)

$+\zeta$ b (a) Fácies biotita monzogranítica equigranular fina a média.

(b) Fácies biotita monzogranítica inequigranular média a fracamente porfiritica, com raros fenocristais de K-feldspato atingindo até $3 \mathrm{~cm}$.

Grupo Seridó

NP3ss Formação Seridó: micaxistos podendo conter granada e/ou cordierita.

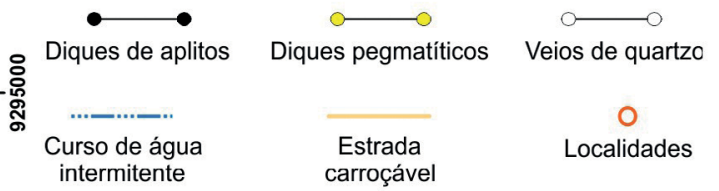

옹

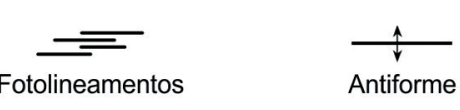

$\leftrightharpoons ; \odot \mid \otimes$ Falha transcorrente sinistral

$\underset{\sim}{\sim} ; \otimes \mid \odot$ Zona de cisalhamento transcorrente dextral

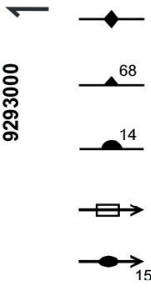

Foliação principal $\left(\mathrm{S}_{3}\right)$ com mergulho vertical

Foliação principal $\left(\mathrm{S}_{3}\right)$ com mergulho medido

Foliação magmática $\left(\mathrm{S}_{\gamma}\right)$ com mergulho medido

Lineação de fluxo magmático $\mathrm{L}_{\gamma}$

Lineação de estiramento mineral $\left(L_{x 3}\right)$ com mergulho medido

ZCCN Zona de Cisalhamento Currais Novos

ZCG Zona de Cisalhamento Gargalheiras

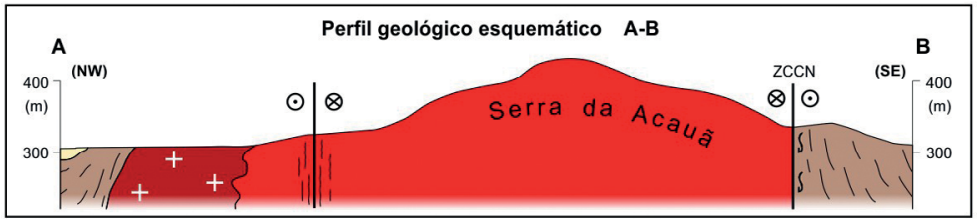

Figura 2. Mapa geológico do Stock Serra da Acauã e sua encaixante (Formação Seridó). 
O plagioclásio ocorre principalmente como cristais hipidiomórficos a xenomórficos, apresentando hábito granular tabular e granulometria variando de 0,2 a $5 \mathrm{~mm}$ ao longo do seu eixo de maior alongamento, com maclas polissintéticas do tipo albita ou periclina. Composicionalmente são oligoclásios com $\mathrm{An}_{25-29 \%}$ (método óptico de Michel-Lévy). É observada zonação normal em boa parte dos cristais, a qual se caracteriza pelas porções centrais descalcificadas e corroídas (saussuritização), acompanhadas da cristalização de mica branca e, mais raramente, carbonato. Comumente apresentam inclusões de quartzo e apatita. Ocorre ainda como pequenos cristais, idio-hipidiomórficos, inclusos no K-feldspato, apresentando finas e irregulares bordas albíticas. É comum, nos contatos com o K-feldspato, desenvolverem textura mirmequítica, em geral bulbosas, com o quartzo vermicular e/ou goticular.
O quartzo se apresenta xenomórfico, granular e com granulação variando de 0,5 a $3,0 \mathrm{~mm}$. Seus cristais desenvolvem contatos intergranulares, de natureza curva, irregular e, em menor número, reta, com plagioclásio e K-feldspato, configurando por vezes textura em mosaico (Figura 6A). Apresentam, no geral, extinção ondulante, a qual, em níveis de strain mais elevados, evolui para textura de subgrãos. Inclusões de plagioclásio, K-feldspato e biotita são comuns.

$\mathrm{O} \mathrm{K}$-feldspato corresponde à microclina (Figura 6B). É representada por fenocristais hipidiomórficos e xenomórficos, responsáveis por atribuir textura fracamente porfirítica às rochas da fácies inequigranular. A sua granulometria varia de 1,5 a $6 \mathrm{~mm}$. O padrão tartan das maclas polissintéticas albita-periclina está por vezes combinado com a macla do tipo carlsbad (Figura 6C). Plagioclásio, biotita, zircão e apatita são as inclusões comuns. É possível observar extinções
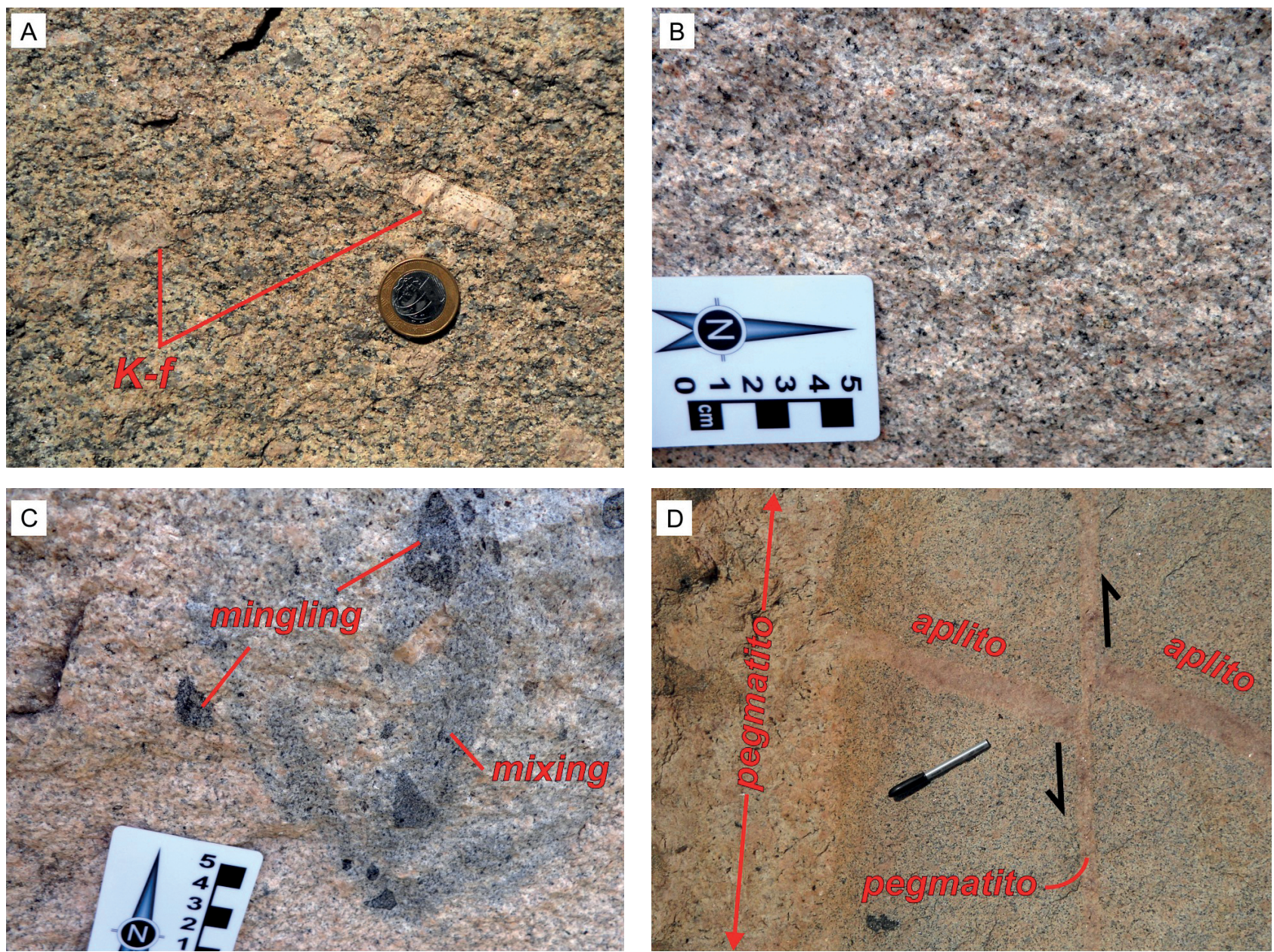

Figura 3. Feições de campo das fácies do Stock Serra da Acauã. (A) Biotita monzogranito inequigranular médio a fracamente porfirítico. Destaque para fenocristais idiomórficos de K-feldspato; (B) biotita monzogranito equigranular fino a médio; (C) feições de mistura de magma (mingling e mixing) envolvendo os enclaves do tipo mafic microgranular enclaves e os monzogranitos; (D) diques de pegmatitos (vertical) cortando dique de aplito, servindo de marcador da cinemática transcorrente sinistral. A tampa da caneta indica o norte. 
Tabela 1. Dados U-Pb em zircões (sensitive high resolution ion micro probe - SHRIMP) dos biotita monzogranitos do Stock Serra da Acauã.

\begin{tabular}{|c|c|c|c|c|c|c|c|c|c|c|c|c|c|c|c|c|c|}
\hline & \multirow{2}{*}{$\begin{array}{c}{ }^{206} \mathrm{~Pb} \\
(\%)\end{array}$} & \multirow{2}{*}{$\begin{array}{c}U \\
(\mathrm{ppm})\end{array}$} & \multirow{2}{*}{$\begin{array}{c}\text { Th } \\
\text { (ppm) }\end{array}$} & \multirow[b]{2}{*}{$\mathrm{Th} / \mathrm{U}$} & \multirow{2}{*}{$\begin{array}{l}{ }^{206} \mathrm{~Pb}^{*} \\
(\mathrm{ppm})\end{array}$} & \multicolumn{6}{|c|}{ Razões } & \multicolumn{6}{|c|}{ Idades (Ma) } \\
\hline & & & & & & $\begin{array}{c}{ }^{207} \mathrm{~Pb} / \\
{ }^{235} \mathrm{U}\end{array}$ & $\pm 1 \sigma$ & $\begin{array}{c}{ }^{206} \mathrm{~Pb} / \\
{ }^{238} \mathrm{U}\end{array}$ & $\pm 1 \sigma$ & $\begin{array}{c}{ }^{207} \mathrm{~Pb} / \\
{ }^{206} \mathrm{U}\end{array}$ & $\pm 1 \sigma$ & $\begin{array}{c}{ }^{207} \mathrm{~Pb} / \\
{ }^{235} \mathrm{U}\end{array}$ & $\begin{array}{l}{ }^{06} \mathrm{~Pb} / \\
{ }^{238} \mathrm{U}\end{array}$ & $\pm 1 \sigma$ & $\begin{array}{l}{ }^{207} \mathrm{~Pb} / \\
{ }^{206} \mathrm{~Pb}\end{array}$ & $\pm 1 \sigma$ & $\begin{array}{c}\text { Conc. } \\
(\%)\end{array}$ \\
\hline \multicolumn{18}{|c|}{$\begin{array}{l}\text { Biotita monzogranítico (EFM) } \\
\mathrm{n}=8\end{array}$} \\
\hline $\mathrm{RC} 1176 \mathrm{~A}-1.1$ & 0,25 & 707,621 & 368,565 & 0,538 & 57,940 & 0,7755 & 1,8 & 0,0951 & 1,4 & 0,0592 & 1,1 & 583 & 585 & 8 & 574 & 25 & 100 \\
\hline RC1176A-3.1 & 0,02 & 1879,377 & 916,391 & 0,504 & 154,941 & 0,7809 & 1,4 & 0,0959 & 1,4 & 0,0590 & 0,4 & 586 & 591 & 8 & 568 & 10 & 99 \\
\hline RC1176A-4.1 & 0,45 & 98,325 & 210,803 & 2,215 & 7,930 & 0,7864 & 3,9 & 0,0934 & 1,8 & 0,0610 & 3,5 & 589 & 576 & 10 & 641 & 75 & 102 \\
\hline RC1176A-5.1 & 0,77 & 1128,180 & 528,004 & 0,484 & 89,947 & 0,7596 & 2,3 & 0,0921 & 1,4 & 0,0598 & 1,8 & 574 & 568 & 8 & 598 & 40 & 101 \\
\hline $\mathrm{RC} 1176 \mathrm{~A}-7.1^{\star \star}$ & 1,12 & 223,948 & 423,012 & 1,952 & 17,165 & 0,7402 & 4,0 & 0,0882 & 1,5 & 0,0609 & 3,7 & 562 & 545 & 8 & 635 & 81 & 103 \\
\hline RC1176A-8.1 & 0,19 & 209,327 & 350,648 & 1,731 & 17,222 & 0,7777 & 2,7 & 0,0956 & 1,5 & 0,0590 & 2,3 & 584 & 588 & 8 & 568 & 49 & 99 \\
\hline RC1176A-10.1 & 0,10 & 546,709 & 180,962 & 0,342 & 44,220 & 0,7622 & 1,7 & 0,0941 & 1,4 & 0,0588 & 1,0 & 575 & 579 & 8 & 559 & 22 & 99 \\
\hline $\mathrm{RC} 1176 \mathrm{~A}-12.1^{\star \star}$ & 1,28 & 271,252 & 192,213 & 0,732 & 20,342 & 0,7020 & 4,3 & 0,0861 & 1,5 & 0,0591 & 4,0 & 540 & 533 & 7 & 571 & 88 & 101 \\
\hline \multicolumn{18}{|c|}{$\begin{array}{l}\text { Biotita monzogranítico (IMFP) } \\
\mathrm{n}=11\end{array}$} \\
\hline$R C-1177 A-1.1$ & 0,329 & 691,400 & 334,114 & 0,499 & 56,382 & 0,7778 & 2,0 & 0,0946 & 1,6 & 0,0596 & 1,2 & 584 & 583 & 9 & 590 & 26 & 100 \\
\hline RC-1177A-2.1 & 0,104 & 532,891 & 296,539 & 0,575 & 43,790 & 0,7800 & 1,9 & 0,0955 & 1,6 & 0,0592 & 1,1 & 585 & 588 & 9 & 575 & 23 & 100 \\
\hline RC-1177A-3.1 & 0,115 & 1698,969 & 627,523 & 0,382 & 139,160 & 0,7781 & 1,7 & 0,0952 & 1,6 & 0,0593 & 0,6 & 584 & 586 & 9 & 577 & 12 & 100 \\
\hline RC-1177A-4.1 & 0,257 & 1370,451 & 873,757 & 0,659 & 111,390 & 0,7679 & 1,8 & 0,0944 & 1,6 & 0,0590 & 0,8 & 578 & 581 & 9 & 568 & 19 & 100 \\
\hline$R C-1177 A-5.1^{\star \star}$ & 0,757 & 714,238 & 476,877 & 0,690 & 55,139 & 0,7372 & 2,8 & 0,0891 & 1,6 & 0,0600 & 2,3 & 561 & 551 & 9 & 603 & 49 & 102 \\
\hline RC-1177A-7.1 & 0,208 & 1149,278 & 568,487 & 0,511 & 93,142 & 0,7777 & 1,8 & 0,0941 & 1,6 & 0,0599 & 0,8 & 584 & 580 & 9 & 601 & 17 & 101 \\
\hline RC-1177A-8.1 & 0,299 & 390,804 & 196,476 & 0,519 & 31,157 & 0,7555 & 2,2 & 0,0925 & 1,6 & 0,0592 & 1,5 & 571 & 570 & 9 & 576 & 33 & 100 \\
\hline RC-1177A-9.1 & 0,069 & 938,735 & 526,059 & 0,579 & 75,989 & 0,7663 & 1,8 & 0,0942 & 1,6 & 0,0590 & 0,7 & 578 & 580 & 9 & 568 & 16 & 100 \\
\hline$R C-1177 A-10.1^{* *}$ & 0,583 & 799,902 & 674,975 & 0,872 & 58,526 & 0,6922 & 2,4 & 0,0846 & 1,6 & 0,0593 & 1,8 & 534 & 524 & 8 & 578 & 39 & 102 \\
\hline RC-1177A-11.1 & 0,254 & 462,187 & 206,518 & 0,462 & 36,251 & 0,7526 & 2,1 & 0,0911 & 1,6 & 0,0599 & 1,4 & 570 & 562 & 9 & 602 & 29 & 101 \\
\hline$R C-1177 A-12.1$ & 0,333 & 526,774 & 364,990 & 0,716 & 41,204 & 0,7370 & 2,2 & 0,0907 & 1,6 & 0,0589 & 1,5 & 561 & 560 & 9 & 564 & 33 & 100 \\
\hline
\end{tabular}

**Amostras não consideradas no cálculo da idade; EFM: fácies equigranular fina a média; IMFP: fácies inequigranular média a fracamente porfirítica.
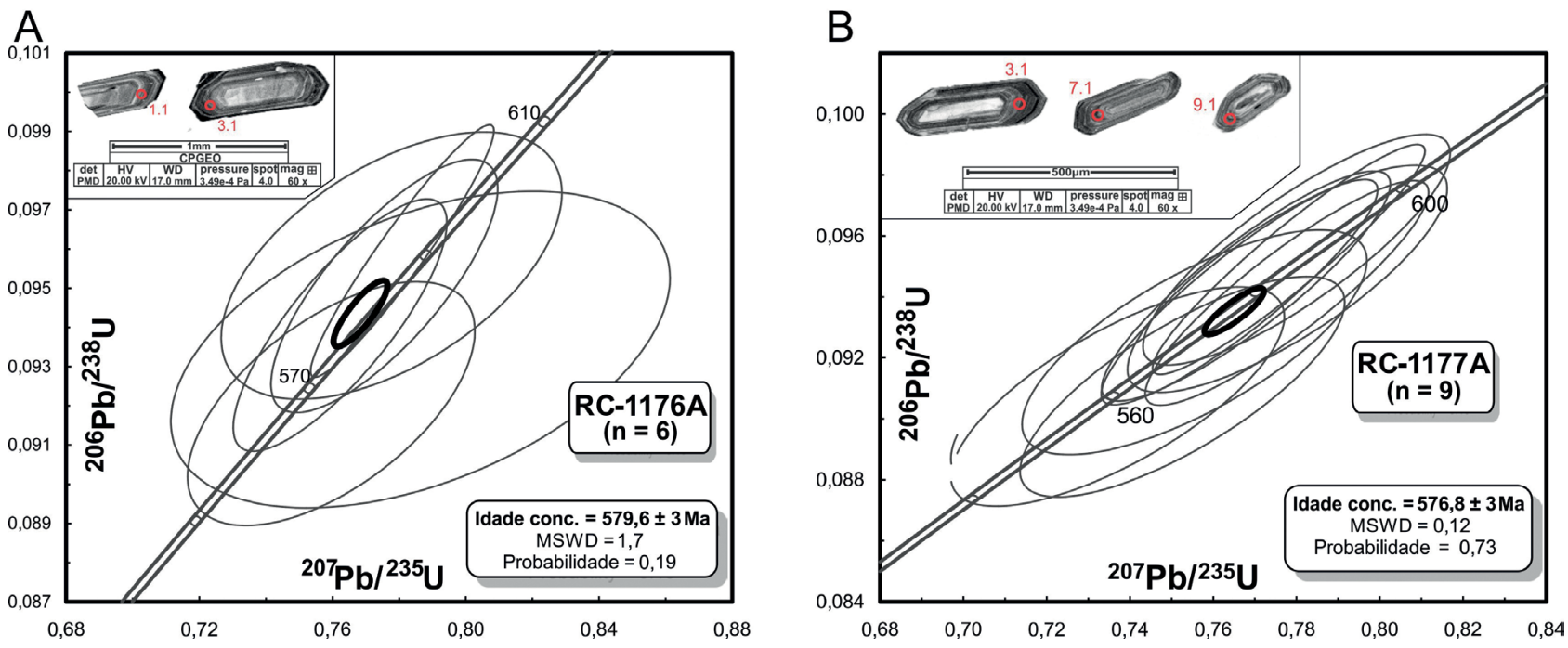

Figura 4. Diagramas concórdia e as respectivas idades $\mathrm{U}-\mathrm{Pb}$ (sensitive high resolution ion micro probe - SHRIMP) em zircão para as fácies equigranular fina a média: $(A)$ este trabalho; (B) fácies inequigranular média a fracamente porfirítica, de Medeiros et al. (2017). 
ondulantes e pertitas tipos fios e filetes. Em alguns cristais, observa-se aspecto de corrosão atribuído às alterações tardimagmáticas para mica branca.

A biotita, fase máfica principal, tem hábito lamelar-ripoide, mediante forma hipidiomórfica e granulometria que varia de 0,2 a 2,0 mm de comprimento. Seu dicroísmo migra de amarelo claro para marrom avermelhado em $x \mathrm{e}$ $z$ ópticos, respectivamente. Cloritização é uma alteração comum, acompanhada da formação de mica branca e de

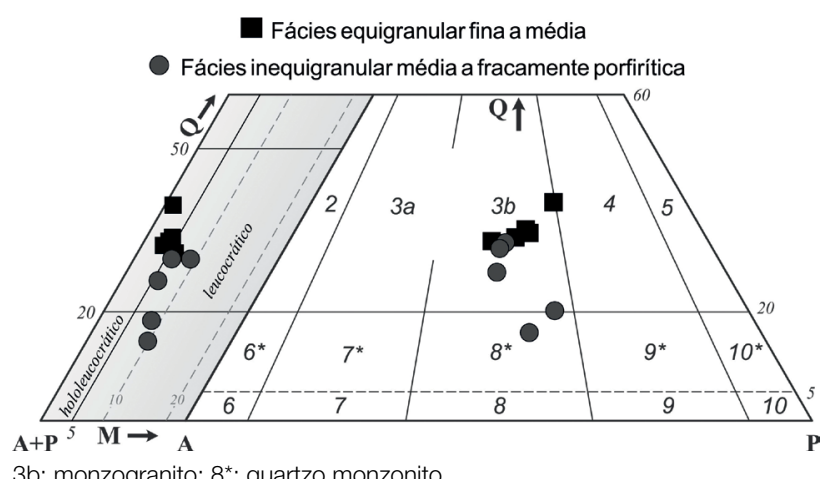

Figura 5. Diagramas de classificação modal Q-A-P e Q-(A+P)-M (Streckeisen, 1976) para as rochas do Stock Serra da Acauã. minerais opacos diminutos ao longo dos seus planos de clivagem (Figura 6D). São observadas inclusões de apatita e zircão, com formação de halo pleocroísmo para o zircão. A titanita é representada por pequenos cristais $(\leq 0,5 \mathrm{~mm})$ idiomórficos a xenomórficos, de hábito losangular e coloração cinza amarronzada fracamente pleocroica e, em alguns casos, com maclas lamelares. Ela ainda ocorre como finas e irregulares coroas associadas ao processo de esfenitização de minerais opacos. Cristais idiomórficos de zircão (menores do que $0,1 \mathrm{~mm}$ ) ocorrem essencialmente como inclusões nas demais fases, especialmente na biotita, onde chega a desenvolver halos pleocricos. Os cristais de allanita são idiomórficos, têm coloração alaranjada e podem atingir tamanhos médios da ordem de $0,2 \mathrm{~mm}$. A apatita ocorre como cristais hipidiomórficos a idiomórficos $(\leq 0,1 \mathrm{~mm})$, desde seções longitudinais prismáticas até seções tabulares hexagonais. Os minerais opacos são hipidiomórficos, com seções quadráticas e, por vezes, losangulares, formando pequenos agregados, em alguns casos associados à titanita. $\mathrm{O}$ tamanho dos cristais varia de 0,1 até $1,0 \mathrm{~mm}$ e podem apresentar inclusões de apatita, zircão e allanita.

Mica branca, clorita e carbonato são fases tardias e secundárias. A mica branca é hipidiomórfica a xenomórfica, de hábito lamelar, cuja granulação varia de 0,1 a 1,0 mm, e está associada à desestabilização de biotita e feldspatos.

Tabela 2. Composição modal dos biotita monzogranítos do Stock Serra da Acauã (foram contados 1.000 pontos por amostra).

\begin{tabular}{|c|c|c|c|c|c|c|c|c|c|c|}
\hline Fácies & & Equigr & llar fine & média & & Inequic & nular $\mathrm{m}$ & ia a fra & mente & firítica \\
\hline Minerais & $\begin{array}{l}\text { MA- } \\
05 A\end{array}$ & $\begin{array}{l}\text { RC- } \\
167 A\end{array}$ & $\begin{array}{r}\text { RC- } \\
168 \mathrm{~A}\end{array}$ & $\begin{array}{l}\text { RC- } \\
176 \mathrm{~A}\end{array}$ & $\begin{array}{c}\text { RC- } \\
180 B\end{array}$ & $\begin{array}{l}\text { MA- } \\
\text { 05B }\end{array}$ & $\begin{array}{l}\text { RC- } \\
174\end{array}$ & $\begin{array}{c}\text { RC- } \\
177 \mathrm{~A}\end{array}$ & $\begin{array}{c}\text { RC- } \\
180 A\end{array}$ & $\begin{array}{l}\text { RC- } \\
182\end{array}$ \\
\hline Quartzo & 32,38 & 33,75 & 39,67 & 33,10 & 31,00 & 25,71 & 14,57 & 18,50 & 29,75 & 29,73 \\
\hline K-feldspato & 29,37 & 26,88 & 20,89 & 26,60 & 32,50 & 34,57 & 33,43 & 28,30 & 29,37 & 31,89 \\
\hline Plagioclásio & 34,38 & 35,00 & 38,11 & 36,00 & 30,33 & 34,00 & 42,14 & 44,60 & 31,75 & 32,24 \\
\hline Biotita & 0,50 & 1,62 & 0,11 & 1,70 & 4,83 & 2,71 & 8,14 & 7,30 & 6,75 & 2,86 \\
\hline Clorita & 1,38 & 0,88 & 0,33 & 0,40 & --- & 0,29 & 0,29 & --- & 0,38 & 0,33 \\
\hline Mica branca & 1,50 & 1,25 & 0,67 & 1,50 & --- & 1,14 & 0,43 & 0,70 & 0,25 & 1,12 \\
\hline Minerais opacos & 0,50 & 0,62 & 0,22 & 0,40 & 0,33 & 0,86 & 1,00 & 0,40 & 1,38 & 1,28 \\
\hline Apatita & TR & TR & TR & TR & TR & TR & TR & TR & TR & TR \\
\hline Zircão & TR & TR & TR & TR & TR & TR & TR & 0,20 & TR & TR \\
\hline Allanita & --- & TR & TR & TR & TR & --- & TR & TR & TR & TR \\
\hline Titanita & --- & TR & --- & 0,10 & 1,00 & 0,71 & TR & TR & 0,38 & 0,55 \\
\hline Carbonato & TR & --- & --- & 0,20 & --- & TR & --- & --- & --- & --- \\
\hline Q & 33,68 & 35,29 & 40,20 & 34,59 & 33,04 & 27,27 & 16,16 & 20,24 & 32,74 & 31,67 \\
\hline$A$ & 30,55 & 28,11 & 21,17 & 27,80 & 34,64 & 36,67 & 37,09 & 30,96 & 32,32 & 33,98 \\
\hline$P$ & 35,76 & 36,60 & 38,62 & 37,62 & 32,32 & 36,06 & 46,75 & 48,80 & 34,94 & 34,35 \\
\hline Q & 32,38 & 33,75 & 39,67 & 33,10 & 31,00 & 25,71 & 14,57 & 18,50 & 29,75 & 29,73 \\
\hline$A+P$ & 63,75 & 61,88 & 59,00 & 62,60 & 62,83 & 68,57 & 75,57 & 72,90 & 61,12 & 64,13 \\
\hline M & 3,88 & 4,37 & 1,33 & 4,30 & 6,16 & 5,71 & 9,86 & 8,60 & 9,14 & 6,14 \\
\hline
\end{tabular}

TR: traços; Q, A, P, M: conforme a proposta de Streckeisen (1976). 
A clorita é pseudomórfica, com forma hipidiomórfica e hábito ripoide, ambos herdados da biotita, com tamanho médio de $0,5 \mathrm{~mm}$. O carbonato está associado unicamente à desestabilização do plagioclásio.

\section{Minerais opacos em seção polida}

As análises ópticas sob luz refletida permitiram reconhecer quatro fases minerais opacas: magnetita (predominante nas duas fácies), ilmenita (observada apenas na fácies EFM), sulfeto (notado no IMFP) e hematita, comum às duas fácies.

A magnetita tem uma granulometria que varia de $\pm 0,1$ até $0,6 \mathrm{~mm}$, apresentando forma hipidiomórfica, hábito quadrático e, por vezes, losangular. Tem coloração cinza-rosada, sem dicroísmo e com reflectância baixa a média típica $( \pm 20 \%)$. Sofre processo incipiente de martitização (hematita) nas bordas e ao longo de seus planos cristalográficos e de fraturas (Figuras 7A, 7B). Inclusões de zircão, apatita e allanita são comuns (Figura 7C).

A ilmenita é granular, ocorre na fácies equigranular fina a média como uma fase opaca subordinada em relação à magnetita. Seus cristais são hipidiomórficos, de coloração cinza clara e desenvolvem contatos retos intergranulares com a magnetita (Figura 7D). Quase todos eles apresentam hematita em finas lamelas de exsolução na forma de filetes, orientadas e de dimensões submicrométricas a micrométricas (máximo de $5 \mu \mathrm{m}$ ). Inclusões de apatita e zircão
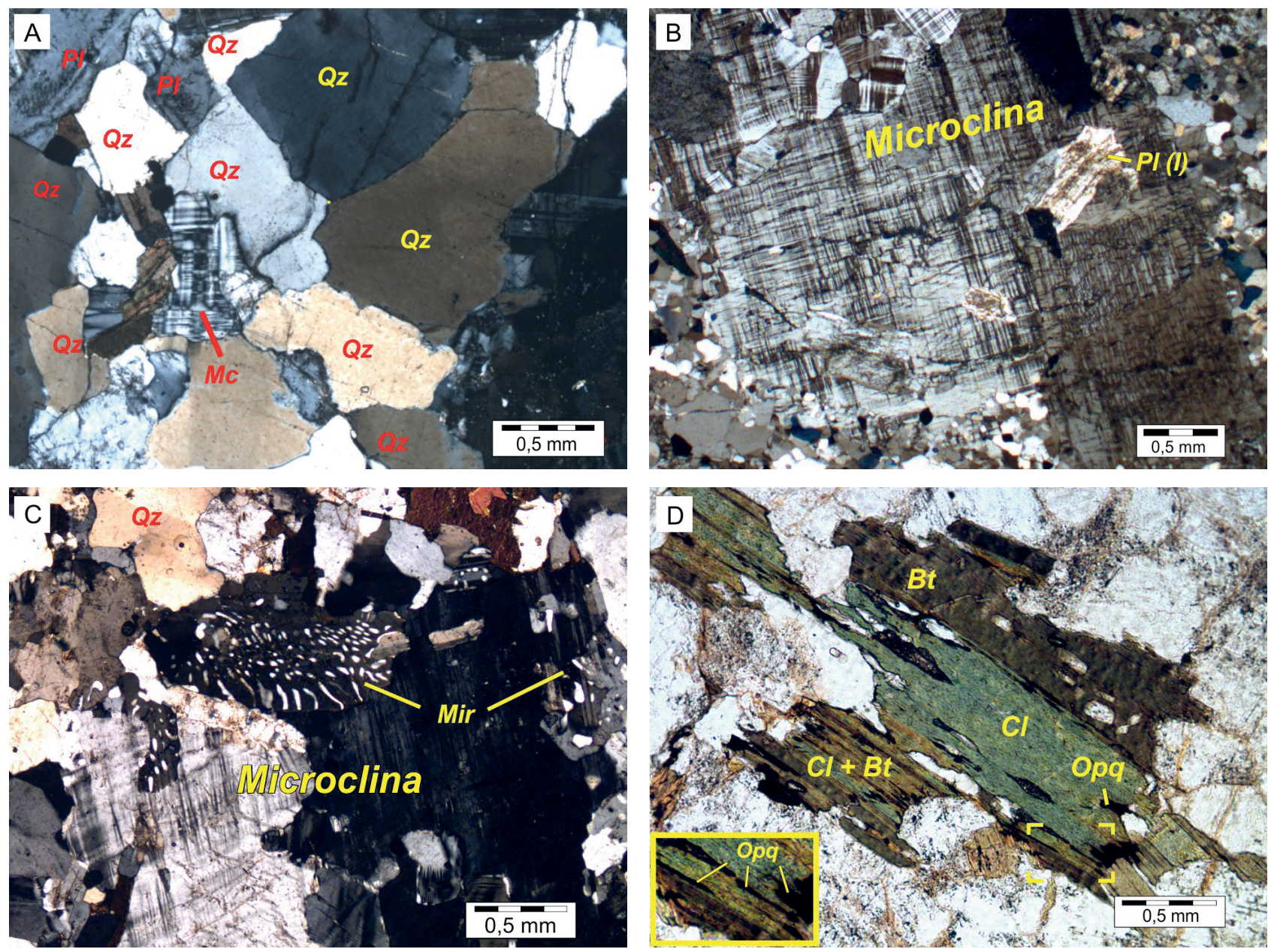

PI: plagioclásio; Qz: quartzo; Mc: microclina; Mir: mirmequitas; Bt: biotita; Cl: clorita; Opq: minerais opacos.

Figura 6. Fotomicrografias das rochas do Stock Serra da Acauã. (A) Cristais xenomórficos fraturados de quartzo formando textura em ponto tríplice [NX]; (B) fenocristal de microclina da fácies inequigranular - a nitidez das geminações albita versus periclina em padrão xadrez (tartan) é sugestiva de uma alta triclinicidade; observa-se inclusões de plagioclásio saussuritizado [NX]; (C) mirmequitas bulbosas, desenvolvidas no contato do plagioclásio com a microclina [NX]; (D) cloritização parcial (porções em verde claro) da biotita (marrom). Minerais opacos ocupam os planos de clivagem da biotita $[\mathrm{N} / /$. 
são observadas. A hematita é observada também distribuída nos cristais de ilmenita, como produto de transformação tardia, associada a um mineral não identificado de coloração cinza mais escura.

Um único grão de sulfeto foi observado incluso na titanita. Sua discreta expressão modal, além do tamanho reduzido $(30 \mu \mathrm{m})$, não permite maiores detalhes sob o aspecto óptico (Figura 8C).

O sistema de microanálise semiquantitativo EDS acoplado ao MEV não só ratificou os dados ópticos, como também revelou variações nos teores médios de manganês na ilmenita, maiores na região onde se encontram as lamelas de exsolução ( 9 a $12 \%$ peso) e menores nas porções onde se encontra hematita associada a $\mathrm{TiO}_{2}(\leq 2 \%$ peso). Comprimentos de onda das linhas características de raios $\mathrm{X} \mathrm{K}_{\alpha}$ para silício, fósforo, cálcio e enxofre, e $\mathrm{L}_{\alpha}$ para o zircônio corroboram a observação das pequenas inclusões de zircão e apatita na magnetita e de sulfeto na titanita.

\section{Geoquímica}

Os resultados das análises geoquímicas das rochas do SSA, bem como o cálculo dos minerais normativos (CIPW) estão apresentados em tabelas na seguinte ordem: elementos maiores, menores e traços (Tabela 3 ), minerais normativos (Tabela 4) e elementos terras raras (ETR) (Tabela 5).
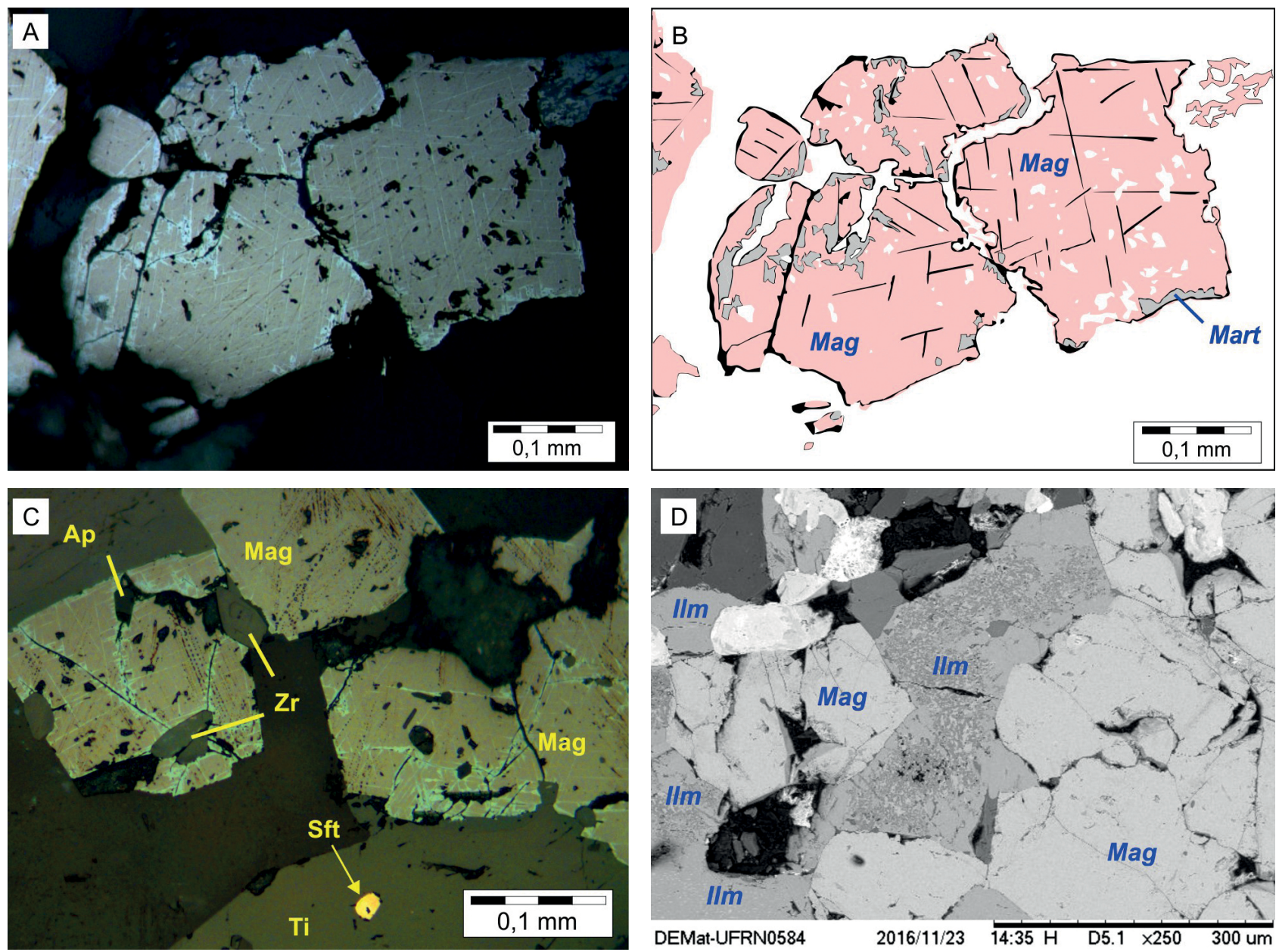

Mag: magnetita; Mart: martitas; Ap: apatita; Zr: zircão; Sft: sulfeto; Ti: titanita; IIm: ilmenita.

Figura 7. Características dos minerais opacos e outras fases associadas do Stock Serra da Acauã. (A) Fotomicrografia (esquerda) exibindo cristais hipidiomórficos a xenomórficos de magnetita da fácies biotita monzogranítica equigranular fina a média. [N//]; (B) desenho esquemático de A realçando as martitas desenvolvidas ao longo da estrutura cristalográfica da magnetita (traços pretos e áreas cinzas); (C) relação entre cristais de magnetita e titanita. Notar inclusões de zircão e apatita no óxido, como também de sulfeto na titanita, na fácies inequigranular média a fracamente porfirítica; (D) imagem de elétrons retroespalhados (backscattering) de microscopia eletrônica de varredura com ilmenita (cinza mais escuro) e magnetita (cinza mais claro) intercrescidos na fácies equigranular fina a média. 

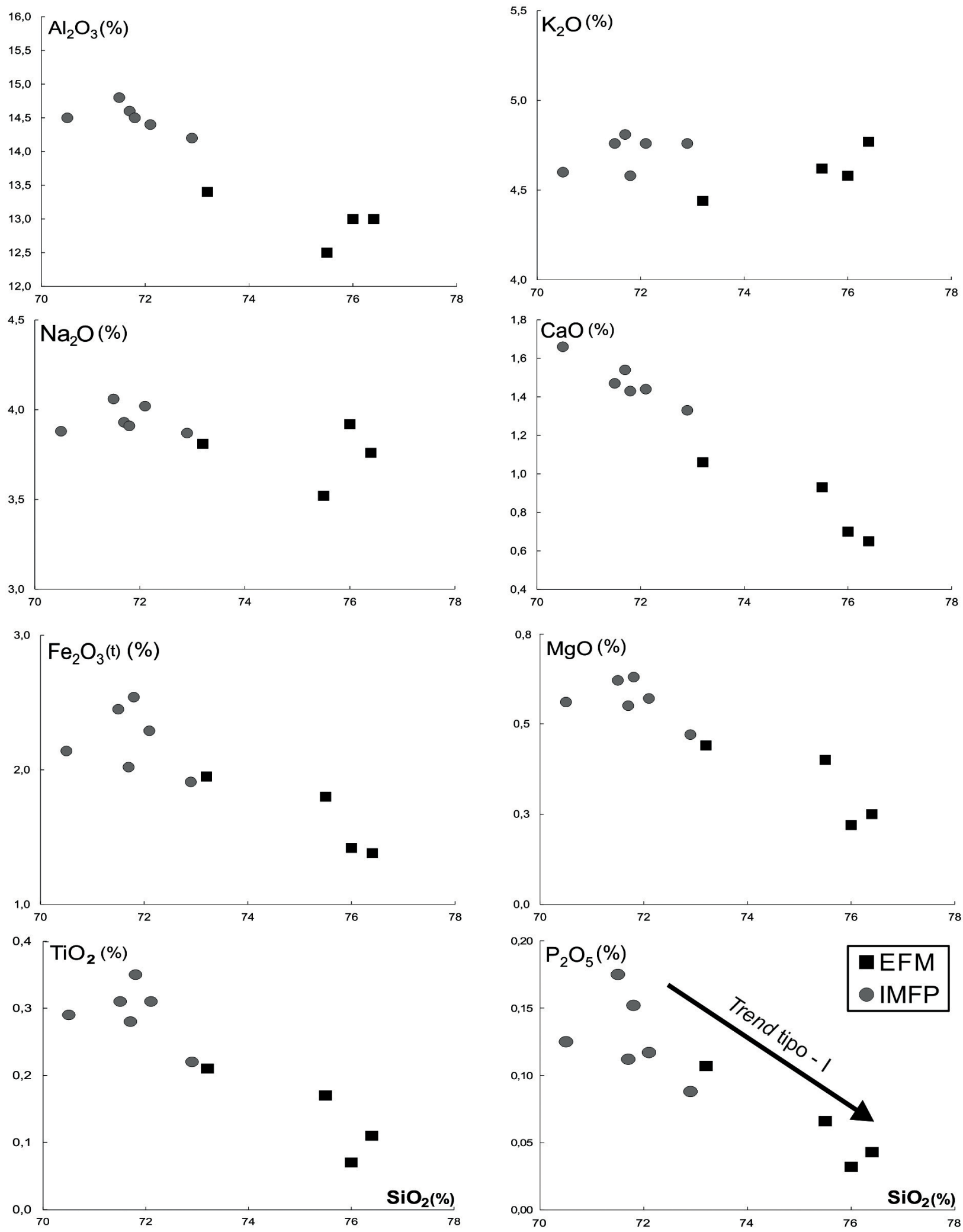

EFM: fácies equigranular fina a média; IMFP: fácies inequigranular média a fracamente porfirítica.

Figura 8. Diagramas do tipo Harker para elementos maiores, com o trend de granitos tipo I para o $\mathrm{P}_{2} \mathrm{O}_{5}$ proposto por Chappell e White (1992). 
Tabela 3. Análises químicas dos biotita monzogranitos do Stock Serra da Acauã.

\begin{tabular}{|c|c|c|c|c|c|c|c|c|c|c|}
\hline \multirow{2}{*}{ Elementos } & \multicolumn{6}{|c|}{ Inequigranular média a fracamente porfirítica } & \multicolumn{4}{|c|}{ Equigranular fina a média } \\
\hline & $\begin{array}{l}\text { RC- } \\
169\end{array}$ & $\begin{array}{c}\text { RC- } \\
180 A\end{array}$ & $\begin{array}{l}\text { RC- } \\
174\end{array}$ & $\begin{array}{c}\text { RC- } \\
177 A\end{array}$ & $\begin{array}{c}\mathrm{RC}- \\
168 \mathrm{~B}\end{array}$ & $\begin{array}{l}\text { RC- } \\
182\end{array}$ & $\begin{array}{l}\text { RC- } \\
166\end{array}$ & $\begin{array}{c}\mathrm{RC}- \\
176 \mathrm{~A}\end{array}$ & $\begin{array}{c}\text { RC- } \\
168 A\end{array}$ & $\begin{array}{c}\text { RC- } \\
167 A\end{array}$ \\
\hline $\mathrm{SiO}_{2}(\%)$ & 70,50 & 71,50 & 71,70 & 71,80 & 72,10 & 72,90 & 73,20 & 75,50 & 76,00 & 76,40 \\
\hline $\mathrm{TiO}_{2}$ & 0,29 & 0,31 & 0,28 & 0,35 & 0,31 & 0,22 & 0,21 & 0,17 & 0,07 & 0,11 \\
\hline $\mathrm{Al}_{2} \mathrm{O}_{3}$ & 14,50 & 14,80 & 14,60 & 14,50 & 14,40 & 14,20 & 13,40 & 12,50 & 13,00 & 13,00 \\
\hline $\mathrm{Fe}_{2} \mathrm{O}_{3(t)}$ & 2,14 & 2,45 & 2,02 & 2,54 & 2,29 & 1,91 & 1,95 & 1,80 & 1,42 & 1,38 \\
\hline $\mathrm{MnO}$ & 0,02 & 0,05 & 0,03 & 0,04 & 0,03 & 0,04 & 0,05 & 0,04 & 0,02 & 0,02 \\
\hline $\mathrm{MgO}$ & 0,56 & 0,62 & 0,55 & 0,63 & 0,57 & 0,47 & 0,44 & 0,40 & 0,22 & 0,25 \\
\hline $\mathrm{CaO}$ & 1,66 & 1,47 & 1,54 & 1,43 & 1,44 & 1,33 & 1,06 & 0,93 & 0,70 & 0,65 \\
\hline $\mathrm{Na}_{2} \mathrm{O}$ & 3,88 & 4,06 & 3,93 & 3,91 & 4,02 & 3,87 & 3,81 & 3,52 & 3,92 & 3,76 \\
\hline $\mathrm{K}_{2} \mathrm{O}$ & 4,60 & 4,76 & 4,81 & 4,58 & 4,76 & 4,76 & 4,44 & 4,62 & 4,58 & 4,77 \\
\hline $\mathrm{P}_{2} \mathrm{O}_{5}$ & 0,13 & 0,18 & 0,11 & 0,15 & 0,12 & 0,09 & 0,11 & 0,07 & 0,03 & 0,04 \\
\hline $\mathrm{PF}$ & 0,72 & 0,36 & 0,44 & 0,51 & 0,62 & 0,53 & 0,58 & 0,49 & 0,47 & 0,47 \\
\hline Total & 99,00 & 100,56 & 100,01 & 100,44 & 100,66 & 100,32 & 99,25 & 100,04 & 100,43 & 100,85 \\
\hline $\mathrm{Ba}(\mathrm{ppm})$ & 1254,00 & 969,00 & 1131,00 & 945,00 & 1137,00 & 892,00 & 495,00 & 307,00 & 131,00 & 140,00 \\
\hline $\mathrm{Ga}$ & 19,80 & 21,10 & 20,60 & 19,10 & 20,00 & 19,00 & 20,20 & 18,60 & 20,70 & 19,20 \\
\hline $\mathrm{Hf}$ & 5,37 & 5,78 & 4,82 & 5,22 & 5,23 & 3,84 & 4,71 & 3,67 & 3,05 & 3,13 \\
\hline $\mathrm{Nb}$ & 23,09 & 29,48 & 20,73 & 27,22 & 29,76 & 20,90 & 31,31 & 25,92 & 14,96 & 23,66 \\
\hline $\mathrm{Rb}$ & 122,80 & 143,50 & 119,70 & 143,70 & 127,80 & 153,70 & 194,30 & 183,70 & 153,10 & 154,60 \\
\hline $\mathrm{Sr}$ & 391,80 & 320,60 & 353,70 & 314,50 & 352,20 & 280,00 & 189,90 & 121,90 & 67,60 & 66,70 \\
\hline Th & 16,10 & 18,20 & 14,10 & 20,10 & 16,60 & 15,50 & 21,30 & 20,40 & 27,70 & 24,90 \\
\hline$U$ & 2,51 & 3,62 & 2,93 & 3,92 & 3,19 & 4,23 & 4,39 & 9,13 & 6,87 & 5,42 \\
\hline $\mathrm{Ta}$ & 1,74 & 2,19 & 1,47 & 2,27 & 2,14 & 1,91 & 2,57 & 2,18 & 1,12 & 1,79 \\
\hline V & 13,00 & 13,00 & 13,00 & 16,00 & 13,00 & 10,00 & 9,00 & 9,00 & 5,00 & 5,00 \\
\hline$Y$ & 5,80 & 6,63 & 5,00 & 7,09 & 5,88 & 9,22 & 5,79 & 2,73 & 1,96 & 2,98 \\
\hline $\mathrm{Zr}$ & 206,70 & 207,90 & 168,00 & 192,60 & 182,20 & 129,90 & 135,70 & 109,10 & 70,00 & 72,70 \\
\hline $\mathrm{Na}_{2} \mathrm{O}+\mathrm{K}_{2} \mathrm{O}$ & 8,48 & 8,82 & 8,74 & 8,49 & 8,78 & 8,63 & 8,25 & 8,14 & 8,50 & 8,53 \\
\hline $\mathrm{K}{ }_{2} \mathrm{O} / \mathrm{Na}_{2} \mathrm{O}$ & 1,19 & 1,17 & 1,22 & 1,17 & 1,18 & 1,23 & 1,17 & 1,31 & 1,17 & 1,27 \\
\hline $\mathrm{A} / \mathrm{CNK}$ & 1,03 & 1,04 & 1,02 & 1,00 & 1,00 & 1,01 & 1,01 & 1,04 & 1,02 & 1,02 \\
\hline A/NK & 1,21 & 1,14 & 1,14 & 1,16 & 1,22 & 1,27 & 1,25 & 1,27 & 1,25 & 1,23 \\
\hline
\end{tabular}

Tabela 4. Composição dos minerais normativos (CIPW) para os biotita monzogranitos do Stock Serra da Acauã.

\begin{tabular}{|c|c|c|c|c|c|c|c|c|c|c|}
\hline Fácies & & quigranu & $r$ média & fracame & te porfir & & & igranular & fina a $m$ & \\
\hline Minerais & $\begin{array}{c}\text { RC- } \\
1169\end{array}$ & $\begin{array}{c}\text { RC- } \\
1180 \mathrm{~A}\end{array}$ & $\begin{array}{c}\text { RC- } \\
1174\end{array}$ & $\begin{array}{c}\text { RC- } \\
1177 \mathrm{~A}\end{array}$ & $\begin{array}{c}\text { RC- } \\
1168 \mathrm{~B}\end{array}$ & $\begin{array}{c}\text { RC- } \\
1182\end{array}$ & $\begin{array}{c}\text { RC- } \\
1166\end{array}$ & $\begin{array}{c}\text { RC- } \\
1176 \mathrm{~A}\end{array}$ & $\begin{array}{c}\text { RC- } \\
1168 \mathrm{~A}\end{array}$ & $\begin{array}{c}\text { RC- } \\
1167 \mathrm{~A}\end{array}$ \\
\hline Quartzo & 26,29 & 25,44 & 26,24 & 27,48 & 26,36 & 28,42 & 31,27 & 34,52 & 33,30 & 33,93 \\
\hline Ortoclásio & 28,86 & 29,36 & 29,74 & 28,35 & 29,34 & 29,34 & 27,71 & 28,48 & 28,02 & 29,07 \\
\hline Albita & 34,01 & 35,03 & 33,96 & 33,88 & 34,60 & 33,32 & 33,26 & 30,33 & 33,56 & 32,04 \\
\hline Anortita & 7,28 & 5,98 & 6,72 & 5,93 & 6,14 & 5,79 & 4,47 & 4,04 & 3,14 & 2,84 \\
\hline Coríndon & 0,30 & 0,47 & 0,26 & 0,59 & 0,21 & 0,33 & 0,44 & 0,11 & 0,26 & 0,37 \\
\hline Hiperstênio & 2,21 & 2,51 & 2,11 & 2,54 & 2,27 & 1,96 & 1,98 & 1,79 & 1,27 & 1,26 \\
\hline Magnetita & 0,48 & 0,54 & 0,45 & 0,57 & 0,51 & 0,42 & 0,44 & 0,40 & 0,32 & 0,30 \\
\hline Ilmenita & 0,32 & 0,33 & 0,30 & 0,37 & 0,33 & 0,23 & 0,22 & 0,18 & 0,07 & 0,12 \\
\hline Apatita & 0,25 & 0,33 & 0,21 & 0,29 & 0,23 & 0,17 & 0,21 & 0,13 & 0,06 & 0,08 \\
\hline Total & 100 & 100 & 100 & 100 & 100 & 100 & 100 & 100 & 100 & 100 \\
\hline
\end{tabular}




\section{Elementos maiores, menores e traços}

As rochas do SSA são ácidas, com $\mathrm{SiO}_{2}$ variando de 70,50 a $76,40 \%$, com as amostras mais diferenciadas pertencentes à fácies EFM. São enriquecidas em álcalis $\left(\mathrm{Na}_{2} \mathrm{O}+\mathrm{K}_{2} \mathrm{O}=8,14\right.$ a $\left.8,82 \%\right)$ com razões $\mathrm{K}_{2} \mathrm{O} / \mathrm{Na}_{2} \mathrm{O}$ entre 1,17 e 1,31 . Apresentam teores moderados de $\mathrm{Al}_{2} \mathrm{O}_{3}(12,50$ a $14,80 \%)$ e discretos de $\mathrm{Fe}_{2} \mathrm{O}_{3(\mathrm{t})}(1,38$ a $2,54 \%), \mathrm{MgO}$ $(\geq 0,63 \%), \mathrm{CaO}(\geq 1,66 \%)$ e $\mathrm{P}_{2} \mathrm{O}_{5}(\geq 0,18 \%)$.

Em diagramas binários de variação (tipo Harker), $\mathrm{Al}_{2} \mathrm{O}_{3}$, $\mathrm{CaO}, \mathrm{Fe}_{2} \mathrm{O}_{3(\mathrm{t})}, \mathrm{MgO}, \mathrm{TiO}_{2}, \mathrm{P}_{2} \mathrm{O}_{5}$ e, em menor grau, $\mathrm{Na}_{2} \mathrm{O}$ expressam correlação negativa com a diferenciação, ao passo que $\mathrm{K}_{2} \mathrm{O}$ mostra um padrão horizontalizado (Figura 8). Os elementos traços $\mathrm{Ba}, \mathrm{Nb}, \mathrm{Sr}, \mathrm{V}, \mathrm{Zr}$ e Hf são compatíveis, ao passo que $\mathrm{Rb}$ e U são incompatíveis (Figura 9).

\section{Saturação em alumina e séries magmáticas}

O índice de saturação em alumina, conhecido por índice de Shand, classifica as rochas do SSA em fracamente peraluminosas $(1,00 \leq \mathrm{A} / \mathrm{CNK} \leq 1,04)$. Tais amostras posicionam-se dentro do intervalo de sobreposição entre granitos tipo I e tipo $\mathrm{S}(\mathrm{A} / \mathrm{CNK}=1$ a 1,1$)$, conforme Chappell e White (1992) e Chappell (1999), ilustrado na Figura 10A. Tal resultado está de acordo com os dados normativos CIPW, com as amostras apresentando valores de coríndon normativo de 0,11 a $0,59 \%$.

No diagrama discriminante de séries magmáticas que correlaciona $\mathrm{SiO}_{2}$ com $\mathrm{K}_{2} \mathrm{O}$, segundo a proposta de Rickwood (1989), as amostras do SSA posicionam-se no campo calcioalcalino de alto $\mathrm{K}$ (Figura 10B), e no diagrama $\mathrm{SiO}_{2}$ versus $\log \left(\mathrm{K}_{2} \mathrm{O} / \mathrm{MgO}\right)$, com campos de Rogers e Greenberg (1981), elas se posicionam entre os campos de série alcalina e calcioalcalina, configurando uma assinatura transicional entre ambos (Figura 10C). Na proposta de Lameyre (1987), as rochas do SSA definem uma linhagem monzonítica, similar àquelas das séries calcioalcalinas de alto $\mathrm{K}$ de Nascimento et al. (2008, 2015) (Figura 10D). Nos diagramas de Frost et al. (2001), as ordenadas $\mathrm{FeO}_{(\mathrm{t})} /\left(\mathrm{FeO}_{(\mathrm{t})}\right.$ $+\mathrm{MgO})$ e $\mathrm{Na}_{2} \mathrm{O}+\mathrm{K}_{2} \mathrm{O}-\mathrm{CaO}$ correlacionam-se com $\mathrm{SiO}_{2}$. Em ambos, as amostras apresentam assinatura de granitos magnesianos e definem uma tendência que flutua entre os campos calcioalcalino e alcalicálcico (Figuras 10E e 10F). Esses diagramas mostram ainda que o SSA tem uma assinatura geoquímica similar aos granitos da suíte calcioalcalina de alto K equigranular de Nascimento et al. (2015).

Whalen et al. (1987) propuseram diagramas geoquímicos, correlacionando o somatório dos elementos traços $\mathrm{Zr}, \mathrm{Nb}$, $\mathrm{Ce}$ e Y com razões de elementos maiores, para discriminar granitos tipo A daqueles dos tipos $\mathrm{S}$, I e M fracionados e não

Tabela 5. Análise química dos elementos terras raras para os biotita monzogranitos do Stock Serra da Acauã.

\begin{tabular}{|c|c|c|c|c|c|c|c|c|}
\hline \multirow{2}{*}{ Fácies } & \multicolumn{5}{|c|}{ Inequigranular média a fracamente porfirítica } & \multicolumn{3}{|c|}{ Equigranular fina a média } \\
\hline & $\begin{array}{c}\mathrm{RC}- \\
1169\end{array}$ & $\begin{array}{c}\text { RC- } \\
1180 \mathrm{~A}\end{array}$ & $\begin{array}{c}\text { RC- } \\
1177 \mathrm{~A}\end{array}$ & $\begin{array}{c}\text { RC- } \\
1168 \mathrm{~B}\end{array}$ & $\begin{array}{c}\text { RC- } \\
1182\end{array}$ & $\begin{array}{c}\text { RC- } \\
1166\end{array}$ & $\begin{array}{c}\text { RC- } \\
1176 \mathrm{~A}\end{array}$ & $\begin{array}{c}\text { RC- } \\
1167 A\end{array}$ \\
\hline La (ppm) & 55,70 & 59,30 & 52,30 & 60,00 & 39,30 & 40,30 & 33,70 & 22,70 \\
\hline $\mathrm{Ce}$ & 87,90 & 96,10 & 100,00 & 92,90 & 61,30 & 60,40 & 53,50 & 32,90 \\
\hline $\operatorname{Pr}$ & 8,69 & 9,23 & 8,54 & 9,26 & 6,18 & 5,77 & 4,80 & 3,03 \\
\hline $\mathrm{Nd}$ & 27,50 & 28,60 & 26,50 & 29,40 & 19,30 & 17,30 & 13,20 & 8,80 \\
\hline $\mathrm{Sm}$ & 3,60 & 3,80 & 3,60 & 4,10 & 3,00 & 2,50 & 1,60 & 1,20 \\
\hline $\mathrm{Eu}$ & 0,92 & 0,84 & 0,88 & 0,93 & 0,72 & 0,47 & 0,33 & 0,24 \\
\hline Gd & 2,43 & 2,43 & 2,48 & 2,53 & 2,16 & 1,73 & 0,99 & 0,90 \\
\hline $\mathrm{Tb}$ & 0,27 & 0,30 & 0,31 & 0,28 & 0,29 & 0,20 & 0,11 & 0,10 \\
\hline Dy & 1,10 & 1,39 & 1,44 & 1,15 & 1,52 & 1,05 & 0,55 & 0,51 \\
\hline $\mathrm{Ho}$ & 0,18 & 0,23 & 0,23 & 0,19 & 0,31 & 0,18 & 0,09 & 0,10 \\
\hline $\mathrm{Er}$ & 0,58 & 0,54 & 0,69 & 0,51 & 0,93 & 0,58 & 0,27 & 0,28 \\
\hline Tm & 0,08 & 0,10 & 0,11 & 0,08 & 0,16 & 0,10 & 0,05 & 0,05 \\
\hline $\mathrm{Yb}$ & 0,50 & 0,60 & 0,60 & 0,50 & 1,00 & 0,50 & 0,30 & 0,30 \\
\hline Lu & 0,08 & 0,08 & 0,09 & 0,07 & 0,15 & 0,09 & 0,05 & 0,06 \\
\hline$\Sigma \mathrm{ETR}$ & 189,53 & 203,54 & 197,77 & 201,90 & 136,32 & 131,17 & 109,49 & 71,12 \\
\hline$(\mathrm{La} / \mathrm{Yb})_{\mathrm{N}}$ & 54,75 & 28,80 & 46,84 & 48,80 & 46,17 & 40,08 & 43,77 & 16,10 \\
\hline$(\mathrm{La} / \mathrm{Sm})_{\mathrm{N}}$ & 10,07 & 11,81 & 13,15 & 9,14 & 9,66 & 9,31 & 9,07 & 8,18 \\
\hline$(\mathrm{Gd} / \mathrm{Yb})_{N}$ & 3,93 & 3,28 & 3,34 & 4,09 & 1,75 & 2,80 & 2,67 & 2,43 \\
\hline $\mathrm{Eu} / \mathrm{Eu}^{*}$ & 0,90 & 0,79 & 0,85 & 0,82 & 0,83 & 0,66 & 0,75 & 0,68 \\
\hline
\end{tabular}

ETR: elementos terras raras; $\mathrm{Eu} / \mathrm{Eu}^{*}=\mathrm{Eu}_{\mathrm{N}} /\left[\left(\mathrm{Sm}_{\mathrm{N}}+\mathrm{Gd}_{\mathrm{N}}\right) / 2\right]$. 
fracionados. Nesse contexto, o conjunto global de amostras do SSA posiciona-se na transição dos granitos não fracionados para granitos fracionados (Figura 11), e com assinatura bem distinta daquela de granitos tipo A.

\section{Elementos terras raras e diagrama multielementos}

Os resultados das análises dos ETR das amostras do SSA foram normalizados em relação ao condrito de McDonough e Sun (1995). O seu somatório apresentou valores que variam de 71,12 a 203,54 ppm, com média geral de 155,10 ppm.
Os resultados revelaram a média de 185,81 ppm para a fácies IMFP, e o valor médio menor de 103,93 ppm, para a EFM, indicando tendência de empobrecimento do conteúdo de ETR total, com o aumento do conteúdo de $\mathrm{SiO}_{2}$.

Os padrões de ETR são caracterizados por um enriquecimento, de cerca de 1 a 300 vezes em relação aos valores do condrito. No geral, os ETR são moderados a fortemente fracionados $\left(\mathrm{La}_{\mathrm{N}} / \mathrm{Yb}_{\mathrm{N}}=16,10\right.$ a 54,75). Os elementos terras raras leves (ETRL) são inclinados, com padrão levemente convexo $\left(\mathrm{La}_{\mathrm{N}} / \mathrm{Sm}_{\mathrm{N}}=8,18\right.$ a 13,15$)$, ao passo que os pesados (ETRP) se apresentam sub-horizontais e suavemente côncavos $\left(\mathrm{Gd}_{\mathrm{N}} / \mathrm{Yb}_{\mathrm{N}}\right.$
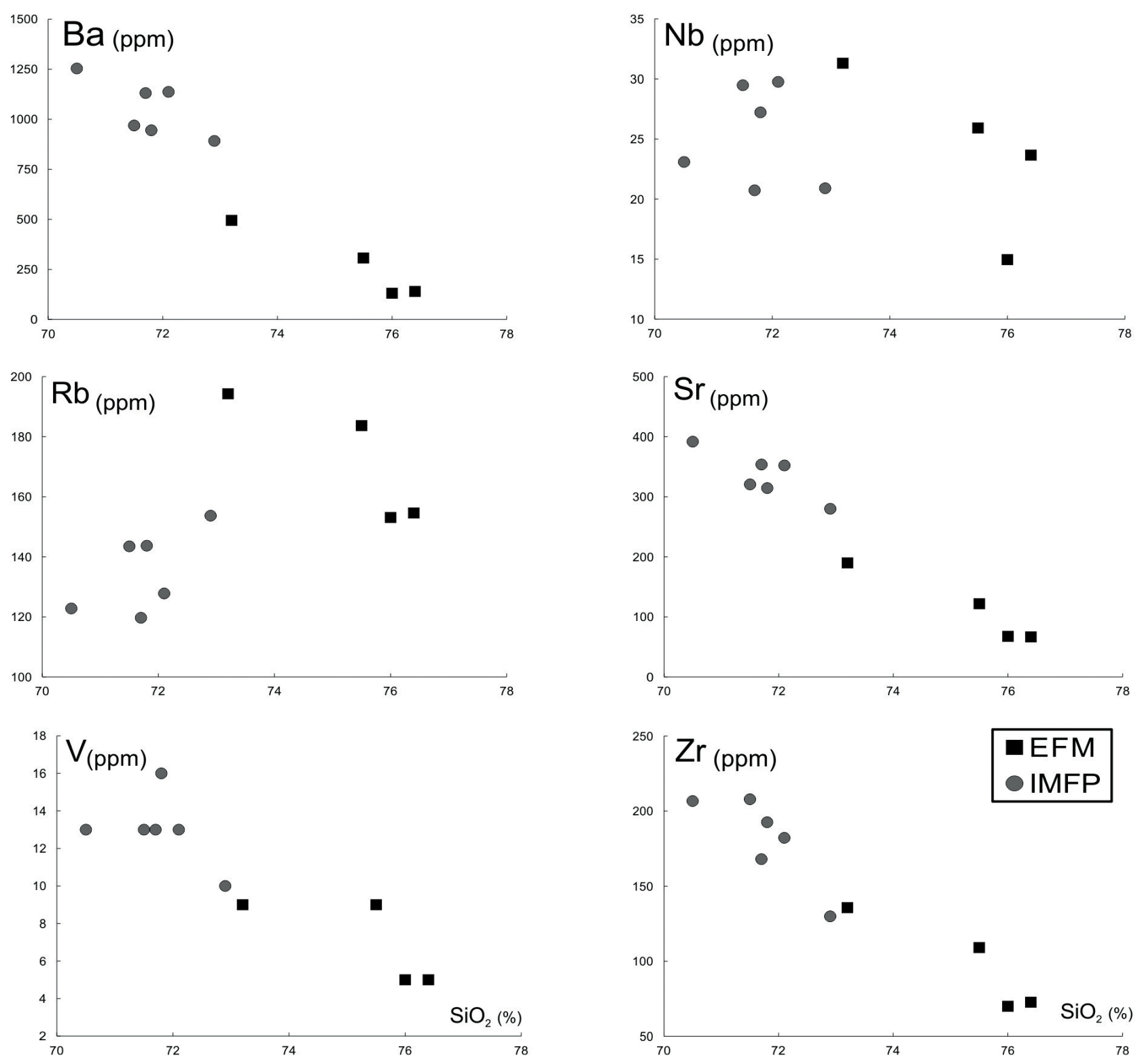

EFM: fácies equigranular fina a média; IMFP: fácies inequigranular média a fracamente porfirítica.

Figura 9. Diagramas do tipo Harker para alguns elementos traços. 
$=1,75$ a 4,09). Os valores de 0,66 a 0,90 para a razão Eu/Eu* (Tabela 5) apontam fracas a moderadas anomalias negativas de Eu (Figura 12A), que aumentam da fácies IMFP para a EFM.

Os aranhogramas normalizados em relação aos valores sugeridos por Thompson (1982) são fracionados e caracterizados por depressões em Nb, Sr, P, Ti (Figura 12B).

\section{Contexto tectônico}

Segundo Pearce et al. (1984), granitos podem ser classificados de acordo com o contexto tectônico no qual estão inseridos. Tais autores desenvolveram diagramas discriminantes de ambientes tectônicos para granitos do
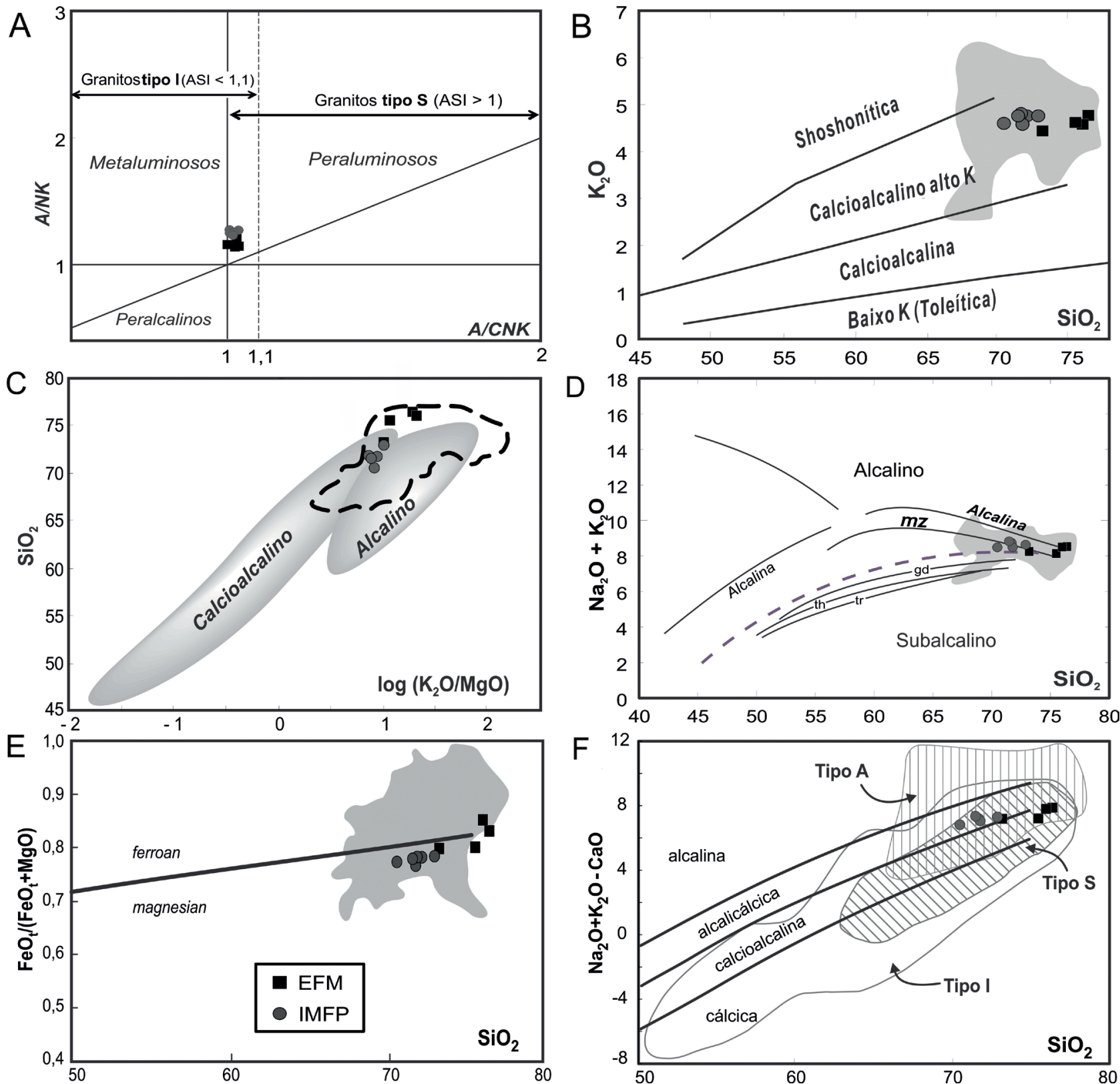

ASI: aluminium saturation index (Hammarstrom e Zen, 1986); EFM: fácies equigranular fina a média; IMFP: fácies inequigranular média a fracamente porfirítica.

Figura 10. Diagramas de saturação em alumina e discriminantes de séries magmáticas para as rochas do Stock Serra da Acauã. (A) Maniar e Piccoli (1989); (B) Rickwood (1989); (C) Rogers e Greenberg (1981); (D) Lameyre (1987); (E) e (F) Frost et al. (2001). As áreas em cinza de B, D e E e tracejada em $C$ refletem o conjunto de amostras da suíte equigranular calcioalcalina de alto potássio equigranular de Nascimento et al. (2015). 
Fanerozoico, com base na química de elementos traços, agrupando essas rochas em quatro grupos principais: granitos de cadeia oceânica, arco vulcânico, intraplaca e colisionais. Não obstante, os próprios autores sinalizaram para uma aplicação apropriada envolvendo granitos do Proterozoico, como é o caso do SSA. As amostras do SSA no diagrama multielementar proposto pelos referidos autores mostra um padrão similar àquele de granitos pós-colisionais (Figura 13A). Da mesma forma, no diagrama $\mathrm{Y}+\mathrm{Nb}$ versus $\mathrm{Rb}$, segundo a proposta de Pearce (1996), as rochas do SSA exibem uma afinidade com os granitoides pós-colisionais (Figura 13B).
Na proposta de Harris et al. (1986), o diagrama ternário $\mathrm{Rb} / 30-\mathrm{Hf}-\mathrm{Ta}(* 3)$ foi originalmente usado para caracterizar rochas intrusivas ácidas a intermediárias de zonas de colisão continente-continente de idade fanerozoica. Nesse sentido, os autores reconheceram quatro grandes grupos de rochas, cada um associado a um estágio particular de evolução tectônica. Nesse diagrama, as amostras do SSA se relacionam ao campo das intrusões calcioalcalinas tardi a pós-colisionais (Figura 13C). De forma similar, em diagramas propostos por Maniar e Piccoli (1989), as rochas do SSA mostram uma assinatura similar à dos granitos pós-orogênicos (Figura 13D).
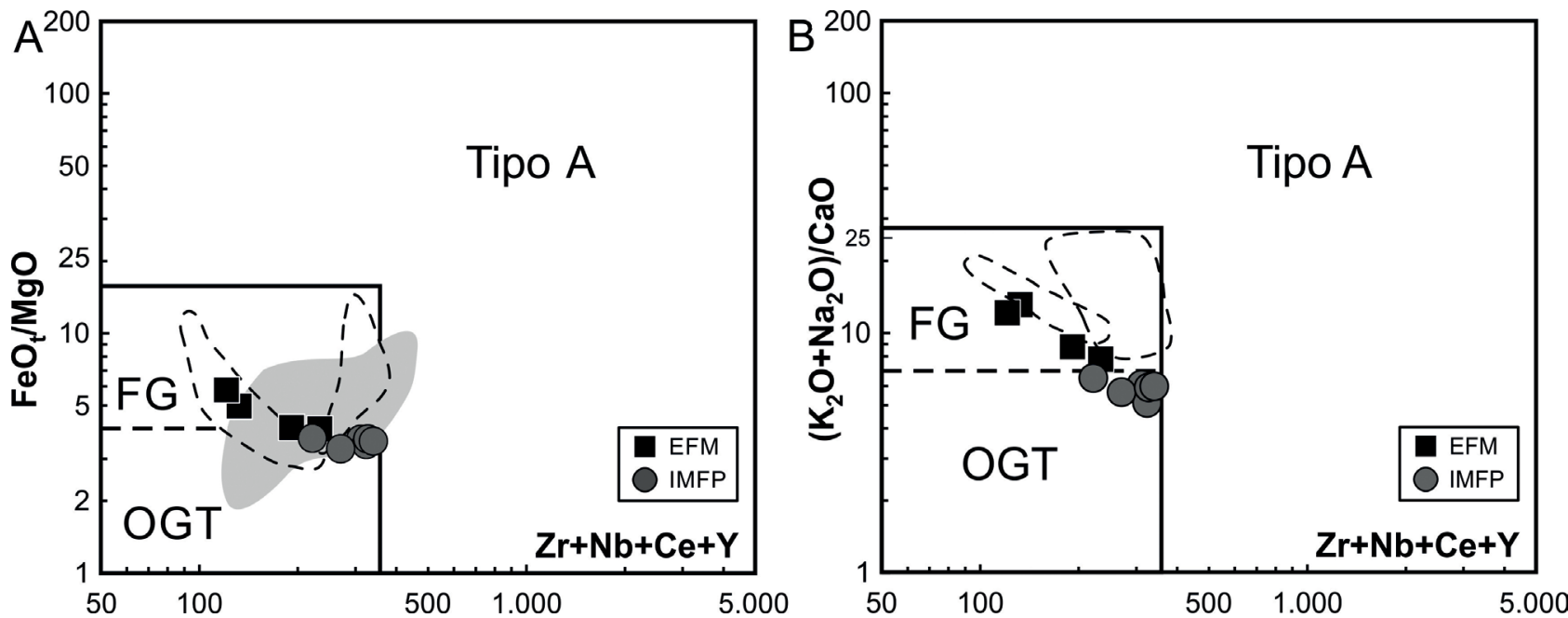

FG: granitos fracionados; OGT: granitos tipo M, I e S não fracionados; EFM: fácies equigranular fina a média; IMFP: fácies inequigranular média a fracamente porfirítica.

Figura 11. Diagramas de discriminação geoquímica, segundo Whalen et al. (1987). As linhas tracejadas em A e B correspondem a campos de granitos fracionados (Whalen et al.,1987); a área cinza em A corresponde a granitos tipo I altamente fracionados do sul da China (Zhou et al., 2016).
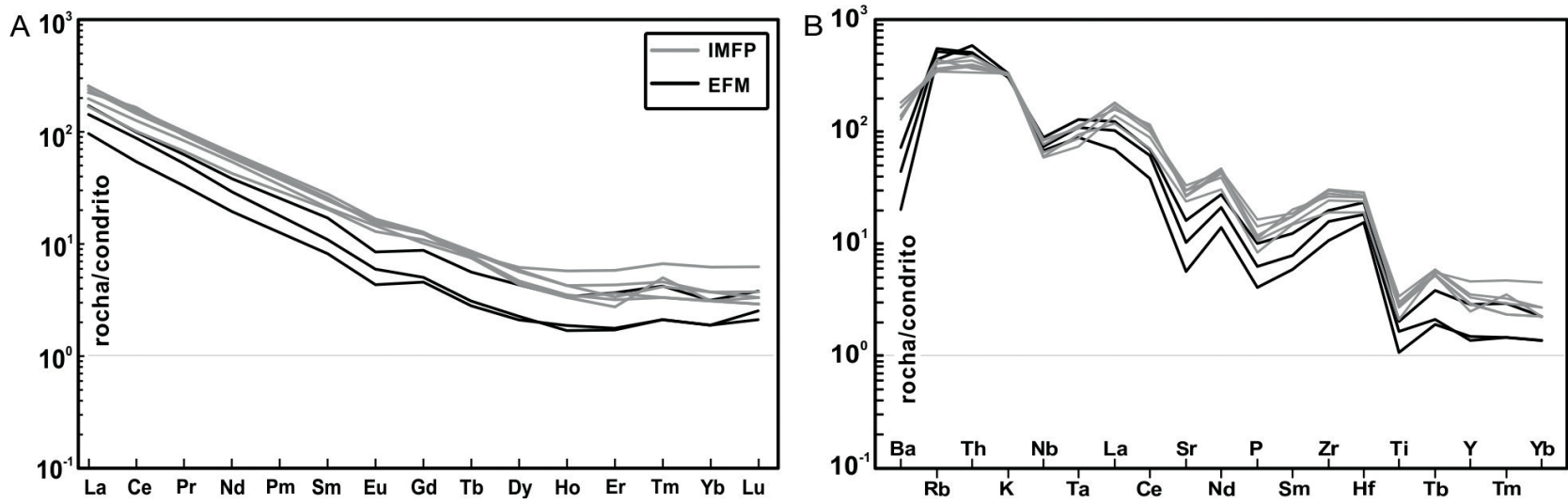

EFM: fácies equigranular fina a média; IMFP: fácies inequigranular média a fracamente porfirítica.

Figura 12. Diagramas para elementos traços incluindo os elementos terras raras para as rochas do Stock Serra da Acauã. (A) Espectro de elementos terras raras normalizados pelo condrito de McDonough e Sun (1995); (B) diagrama multielementar normalizado segundo Thompson (1982). 


\section{Condições de cristalização}

As condições de cristalização foram inferidas com base em três parâmetros físicos: pressão de cristalização, temperaturas de liquidus e solidus e fugacidade de oxigênio $\left(f \mathrm{O}_{2}\right)$.

Para as estimativas de pressão de cristalização, foram levados em consideração dados normativos CIPW de Qz-Ab-Or, considerando um sistema haplogranítico. Tal condição é fundamentada na característica petrográfica, que consiste na presença de dois feldspatos coexistindo em equilíbrio com quartzo, característico de granito subsolvus.
O geobarômetro proposto por Yang (2017) baseia-se na aplicação de duas equações polinomiais: $\mathrm{P}_{1}=-0,2426^{*}(\mathrm{Qz})^{3}$ $+26,392 *(\mathrm{Qz})^{2}-980,74 *(\mathrm{Qz})+12563$ e $\mathrm{P}_{2}=0,2426^{*}(\mathrm{Ab}$ + Or $)^{3}-46,397 *(\mathrm{Ab}+\mathrm{Or})^{2}+2981,3 *(\mathrm{Ab}+$ Or $)-64224$, com $\mathrm{R}^{2}=0,9943$. Aplicando essas equações para as rochas do SSA, foram encontradas pressões de cristalização entre 2 e 4 kbar. Por outro lado, a utilização do geobarômetro de Tuttle e Bowen (1958), no diagrama ternário Qz-Ab-Or, revelou pressões de cristalização maiores, no geral entre 3 e 5 kbar (Figura 14A), mais compatíveis com o sistema de subsolvus graníticos.
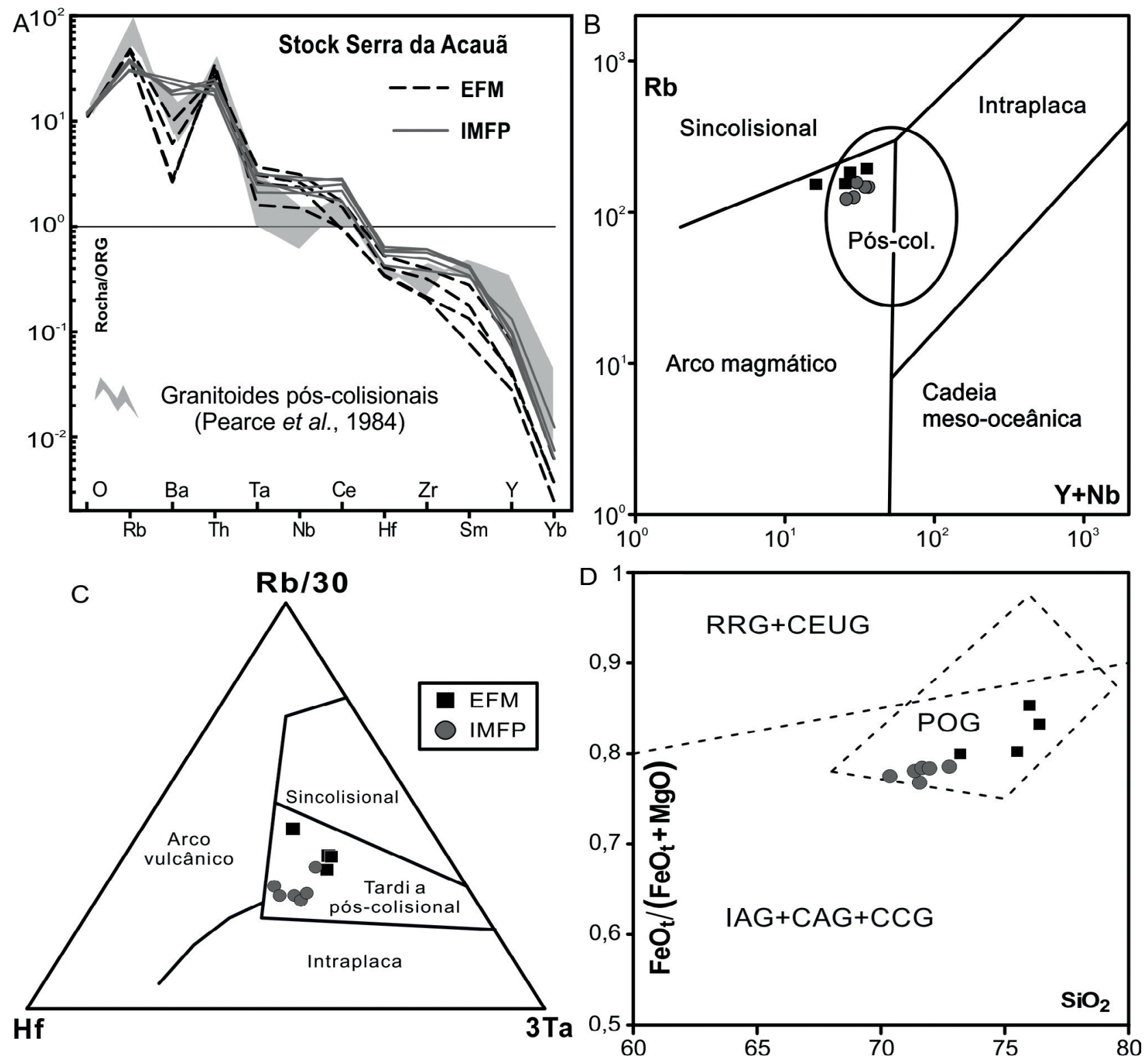

EFM: fácies equigranular fina a média; IMFP: fácies inequigranular média a fracamente porfirítica; IAG: island arc granitoids; CAG: continental arc granitoids; CCG: continental collision granitoids; RRG: rift-related granitoids; CEUG: continental epeirogenic uplift granitoids.

Figura 13. Contexto tectônico das rochas do Stock Serra da Acauã. (A) Diagrama multielementar para granitoides pós-colisionais, segundo Pearce et al. (1984); (B) Pearce (1996); (C) Harris et al. (1986); (D) Maniar e Piccoli (1989). 
Geotermômetros que levam em consideração a saturação de zircão (Watson e Harrison, 1983) e de apatita (Watson e Harrison, 1984), durante o resfriamento magmático, foram empregados para inferir temperaturas mais próximas do liqui$d u s$ para as rochas do SSA, partindo do princípio de que tais fases foram consideradas precoces na sequência de cristalização. Todas as amostras analisadas do SSA estão no intervalo calibrado por Siégel et al. (2018), com razão catiônica $\mathrm{M}=(\mathrm{Na}+\mathrm{K}+2 \mathrm{Ca}) /(\mathrm{Al} * \mathrm{Si})$ entre 0,9 e 1,9 . De todo, os dados envolvendo temperaturas de saturação de zircão e apatita do SSA apontam valores entre 750 e $950^{\circ} \mathrm{C}$ (Figuras 14B e 14C).

Para inferir as temperaturas próximas do solidus, foram utilizados dados normativos CIPW de rocha total, os quais foram plotados no diagrama Qz-Ab-Or, segundo a proposta de Luth et al. (1964). Os valores de temperatura aqui obtidos variam de 680 a $700^{\circ} \mathrm{C}$ (Figura 14D).
As condições de $f \mathrm{O}_{2}$ referentes à evolução magmática dos biotitas monzogranitos do SSA foram inferidas com base na mineralogia de suas rochas. A substituição parcial de ilmenita por titanita, em equilíbrio com cristais de magnetita e quartzo, somada ao processo de martitização, sugere uma $\mathrm{fO}_{2}$ relativamente alta para o magma progenitor (Wones, 1989).

\section{DISCUSSÃO E CONCLUSÕES}

Um caráter deformacional dúctil ocasionado pelas zonas de cisalhamento Gargalheiras e Currais Novos se restringe às rochas da encaixante (Formação Seridó), não afetando o plutão Serra da Acauã. O referido corpo apresenta um domínio estrutural exclusivamente rúptil dominado por falhas E-W, fraturas e diques, o que permite caracterizar o
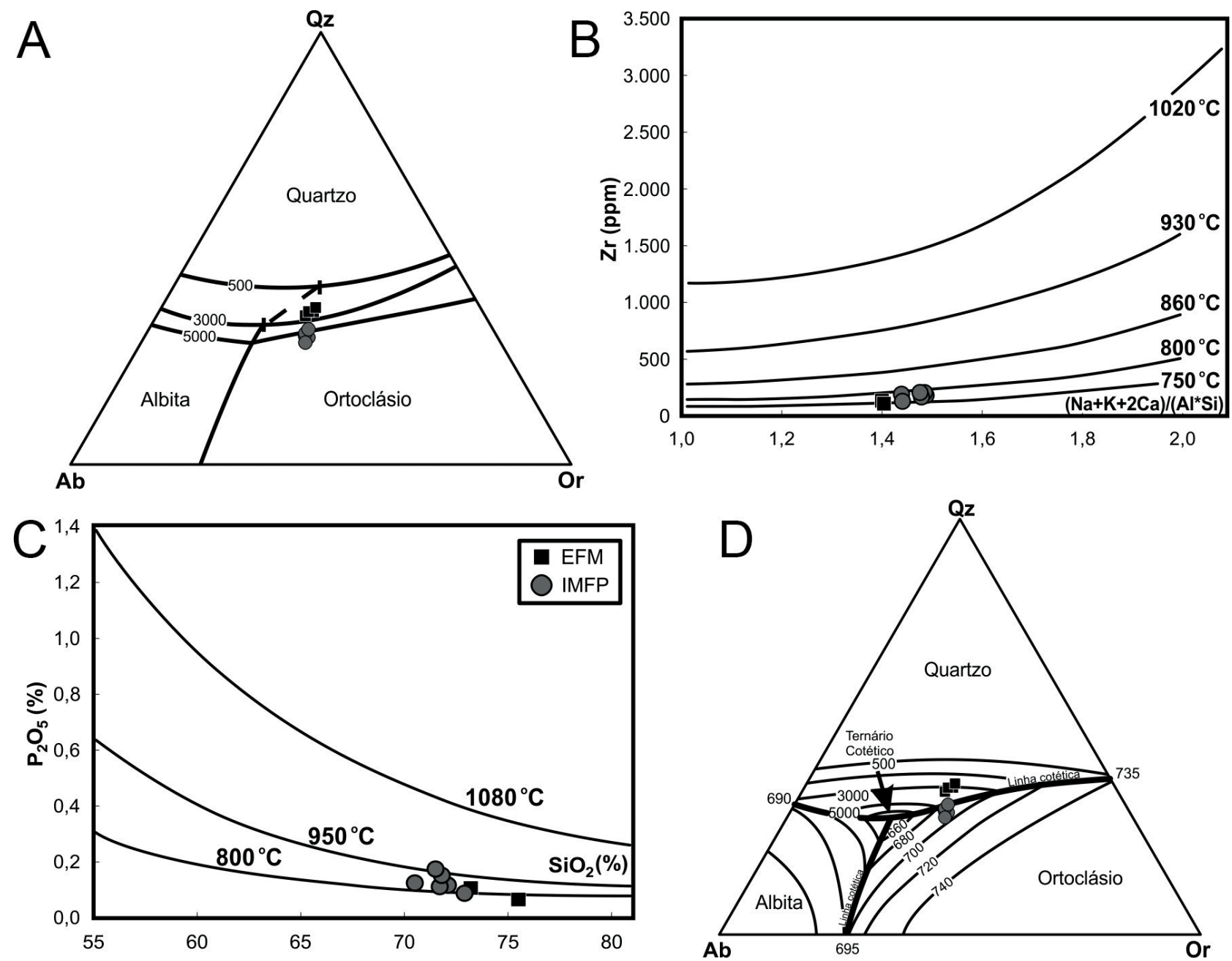

EFM: fácies equigranular fina a média; IMFP: fácies inequigranular média a fracamente porfirítica.

Figura 14. Diagramas de pressão e temperatura para as rochas do Stock Serra da Acauã. (A) Diagrama normativo para pressão, segundo Tuttle e Bowen (1958); geotermômetros de saturação de zircão e apatita, respectivamente: (B) Watson e Harrison (1983) e (C) Watson e Harrison (1984); (D) diagrama normativo para temperatura, conforme Luth et al. (1964). 
seu alojamento como tarditectônico no contexto da orogênese Brasiliana na PB. A orientação preferencial dos fenocristais de $\mathrm{K}$-feldspatos observada na fácies porfirítica estaria associada a um fabric de fluxo magmático.

As determinações U-Pb em zircão apontaram uma idade ediacarana de $578 \pm 4$ Ma para a cristalização do SSA, muito próxima daquelas encontradas para vários outros plutões do DPS como os granitoides Acari $(577 \pm 5 \mathrm{Ma})$, Serra da Rajada (557 $\pm 3 \mathrm{Ma})$, Flores (553 $\pm 4 \mathrm{Ma}$ ) e Serra do Caramurú (553 $\pm 10 \mathrm{Ma}$ ) (Archanjo et al., 2013, Costa et al., 2015; Souza et al., 2016).

As duas fácies do SSA mostram composição modal semelhante e assinaturas geoquímicas similares, o que nos leva a considerá-las como comagmáticas.

Os diagramas de variação do tipo Harker mostraram correlações negativas para $\mathrm{Al}_{2} \mathrm{O}_{3}, \mathrm{CaO}, \mathrm{Fe}_{2} \mathrm{O}_{3(t)}, \mathrm{MgO}, \mathrm{TiO}_{2}$, $\mathrm{P}_{2} \mathrm{O}_{5}, \mathrm{Zr}, \mathrm{Sr}, \mathrm{V}$ e Ba, sugerindo fracionamento de plagioclásio, acompanhado das fases máficas primárias, em especial biotita, titanita, apatita, zircão e minerais opacos durante o processo de evolução do magma. Os diagramas geoquímicos discriminantes de séries/associações magmáticas, por sua vez, são consistentes com um quimismo transicional entre rochas das séries alcalinas e calcioalcalinas, sendo aqui denominadas calcioalcalinas de alto potássio (também relatadas na literatura como subalcalinas, transalcalinas ou monzoníticas).

As rochas do SSA são bastante evoluídas $(>70,50 \%$ de $\mathrm{SiO}_{2}$ ), apresentam baixo $\mathrm{CaO}$ e $\mathrm{Fe}_{2} \mathrm{O}_{3(\text { (t) }}$ (Tabela 4), são enriquecidas em álcalis com razões $\mathrm{K}_{2} \mathrm{O} / \mathrm{Na}_{2} \mathrm{O}>1$, 0 ; de caráter fracamente peraluminoso e de linearidade negativa para $\mathrm{P}_{2} \mathrm{O}_{5}$ (Figura 8), compatíveis com granitos do tipo I. Tais características assemelham-se às de granitos tipo I fracionados de Whalen et al. (1987), Chappell e White (1992), Chappell (1999), Zhu et al. (2009), Li et al. (2007), Zhang et al. (2015) e Zhou et al. (2016). Ainda nesse contexto de tipologias de granitos, o stock mostra afinidade com magnetita granitos (granitos oxidados) dos autores japoneses Ishihara $(1977,1981)$ e Takahashi et al. (1980).

Os padrões dos ETR mostram enriquecimento dos ETRL em relação aos ETRP, com razões $\mathrm{La}_{\mathrm{N}} / \mathrm{Yb}_{\mathrm{N}}$ entre 16,10 e 54,75 , e fracas a moderadas anomalias negativas de $\mathrm{Eu}$ (Eu/Eu* entre 0,66 e 0,90), compatíveis com fracionamento de plagioclásio. O paralelismo nos padrões de ETRs sugere uma mesma fonte e subsequente diferenciação similar para ambas as fácies do plutão. A inclinação global negativa do espectro e a concavidade convexa no intervalo dos ETRP podem ser explicadas pela presença de allanita e o fracionamento de apatita. Além disso, as anomalias negativas de $\mathrm{Nb}$, $\mathrm{Sr}$, P, Ti observadas no diagrama multielementos também podem indicar fracionamento de apatita ( $\mathrm{Sr}$ e $\mathrm{P}$ ) e titanita ( $\mathrm{Nb}$ e Ti), além de serem análogas a granitos tipo I fracionados do nordeste da China (Wu et al., 2003).

Diagramas discriminantes de ambientes tectônicos indicam que o SSA é orogênico de caráter tardi a pós-tectônico em relação à orogênese Brasiliana, aliando-se às características de campo observadas e de sua idade.

As temperaturas de saturação de zircão, para os monzogranitos, são, em média, menores do que aquelas apresentadas para saturação de apatita, estando contidas no intervalo de 753 a $803^{\circ} \mathrm{C}$. Tal intervalo corresponde a um regime similar ao de granitos tipo I altamente fracionados do sul da China (Li et al., 2007; Zhu et al., 2015) (Figura 15).

Os resultados obtidos para as pressões mínimas de cristalização, por meio do diagrama de Tuttle e Bowen (1958), entre 3 e 5 kbar, permitiram estimar uma profundidade de alojamento (h) de 11,6 a 19,3 km para o SSA, onde $\mathrm{h}=\mathrm{P} /(p \mathrm{~g})$; e considerando-se uma densidade média ( $p$ ) de $2,65 \mathrm{~g} / \mathrm{cm}^{3}$, conforme dados de outros corpos no DPS de características petrográficas e texturais similares (Souza, 2016; Maia, 2004, por exemplo). Tais valores, além de serem mais compatíveis com sistemas de subsolvus graníticos do que aqueles menores (em média) obtidos pela aplicação da metodologia de Yang (2017), estão em consonância com as pressões obtidas por Cavalcante et al. (2014), Costa et al. (2015) e Souza et al. (2017) em granitoides ediacaranos do extremo nordeste da PB.

No tocante às condições de fugacidade de oxigênio, verificamos na rocha a presença da paragênese titanita + magnetita + quartzo em equilíbrio, além de processos de martitização associados aos cristais de magnetita. Essas feições indicam condições de $f \mathrm{O}_{2}$ relativamente elevadas durante a evolução/cristalização do magma granítico.

O processo sugerido para a evolução magmática do SSA é a cristalização fracionada, em virtude da presença principalmente de cristais zonados de plagioclásio, K-feldspato e allanita. Por outro lado, sua interação com enclaves do tipo MME (oriundos da fusão parcial do manto superior)

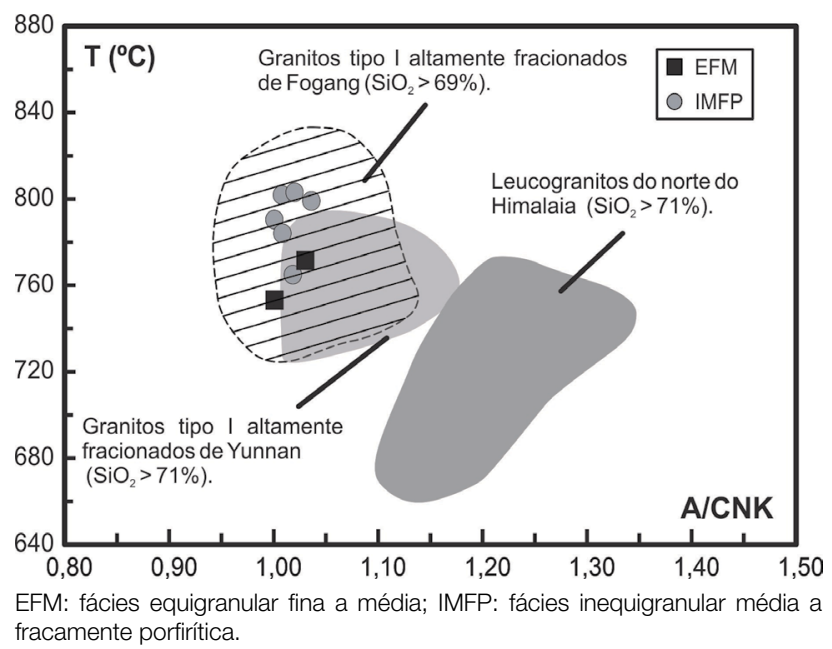

Figura 15. Diagrama A/CNK versus temperaturas de saturação em zircão para o Stock Serra da Acauã, segundo Zhu et al. $(2009,2015)$. 
produzindo localmente misturas tipo mixing e mingling sugere uma evolução mista para o magmatismo, a saber, cristalização fracionada (dominante) e mistura de magmas (restrita).

\section{AGRADECIMENTOS}

Os autores agradecem ao Serviço Geológico do Brasil (CPRM) e ao Programa de Pós-Graduação em Geodinâmica e Geofísica (PPGG), o apoio e a concessão de dados. Mateus de Araújo Silva agradece à Coordenação de Aperfeiçoamento de Pessoal de Nível Superior (CAPES) a bolsa de estudos concedida.

\section{REFERÊNCIAS}

Almeida, F. F. M., Hasui, Y., Brito Neves, B. B., Fuck, R. A. (1981). Brazilian structural provinces: an introduction. Earth-Science Reviews, 17(1-2), 1-29. https://doi. org/10.1016/0012-8252(81)90003-9

Almeida, F. F. M., Leonardos Jr., O. H., Valença, J. (1967). Review on granitic rocks of northeast South America. Haarlem: International Union of Geological Sciences.

Angelim, L. A. A., Nesi, J. R., Torres, H. H. F., Medeiros, V. C., Santos, C. A., Veiga Júnior, J. P., Mendes V. A. (2006). Geologia e recursos minerais do Estado do Rio Grande do Norte - Escala 1:500.000. Texto explicativo dos mapas geológico e de recursos minerais do Estado do Rio Grande do Norte. Recife: CPRM - Serviço Geológico do Brasil.

Archanjo, C. J., Hollanda, M. H. B. M. (2015). Idade do Complexo Caicó (Faixa Seridó, RN-PB) com base no método $\mathrm{U} / \mathrm{Pb}$ (SHRIMP) em zircão de ortognaisses. XXVI Simpósio de Geologia do Nordeste, 24,160 p. Anais... Natal: SBG/ Núcleo Nordeste.

Archanjo, C. J., Viegas, L. G. F., Hollanda, M. H. B. M., Souza, L. C., Liu, D. (2013). Timing of the HT/LP transpression in the Neoproterozoic Seridó Belt (Borborema Province, Brazil): constraints from U-Pb (SHRIMP) geochronology and implications for the connections between NE Brazil and West Africa. Gondwana Research, 23(2), 701-714. https:// doi.org/10.1016/j.gr.2012.05.005

Bizzi, L. A., Schobbenhaus, C., Vidotti, R. M., Gonçalves, J. H. (2003). Geologia, Tectônica e Recursos Minerais do Brasil: texto, mapas e SIG. Brasília: CPRM - Serviço Geológico do Brasil.

Campos, B. C. S., Vilalva, F. C. J., do Nascimento, M. A. L., Galindo, A. C. (2016). Crystallization conditions of porphyritic high-K calc-alkaline granitoids in the extreme northeastern Borborema Province, NE Brazil, and geodynamic implications. Journal of South American Earth Sciences, 70, 224-236. https://doi.org/10.1016/j.jsames.2016.05.010

Cavalcante, R., Galindo, A. C., Alves da Silva, F. C. A., Souza, R. F. (2014). Química mineral e condições de cristalização do Pluton Granítico Barcelona, extremo nordeste da Província Borborema, Nordeste do Brasil. Pesquisas em Geociências, 41(3), 257-272. https://doi.org/10.22456/1807-9806.78102

Cavalcante, R., Medeiros, V. C., Costa, A. P., Sá, J. M., Santos, R. V., Rodrigues, J. B., Dantas, A. R., Nascimento, M. A. L., Cunha, A. L. C. (2018). Neoarchean, Rhyacian and Neoproterozoic units of the Saquinho region, eastern Rio Piranhas-Seridó domain, Borborema Province (northeastern Brazil): implications for the stratigraphic model. Journal of the Geological Survey of Brazil, 1(1), 11-29. https://doi.org/10.29396/jgsb.2018.v1.n1.2

Chappell, B. W. (1999). Aluminium saturation in I- and S-type granites and the characterization of fractionated haplogranites. Lithos, 46(3), 535-551. https://doi.org/10.1016/ s0024-4937(98)00086-3

Chappell, B. W., White, A. J. R. (1992). I- and S-type granites in the Lachlan Fold Belt. Geological Society of America, 272, 1-26. https://doi.org/10.1130/spe272-p1

Costa, A. P., Nascimento, M. A. L., Galindo, A. C., Dantas, A. R. (2015). Geologia, petrologia e geocronologia U-Pb do Plúton Granítico Serra da Rajada: implicações sobre a evolução magmática ediacarana na porção NE do Domínio Rio Piranhas-Seridó (NE da Província Borborema). Geologia USP. Série Cientifica, 15(3-4), 83-105. https://doi.org/10.11606/ issn.2316-9095.v15i3-4p83-105

Dantas, E. L. (1992). Evolução tectonomagmática do maciço polidiapírico São Vicente/Florânia-RN. Dissertação (Mestrado). Rio Claro: UNESP.

Delgado, I. M., Souza, J. D., Silva, L. C., Silveira Filho, N. C., Santos, R. A., Pedreira, A. J., Guimarães, J. T., Angelim, L. A. A., Vasconcelos, A. M., Gomes, I. P., Lacerda Filho, J. V., Valente, C. R., Perrotta, M. M., Heineck C. A. (2003). Geotectônica do Escudo Atlântico. In: L. A. Bizzi (Ed.), Geologia, Tectônica e Recursos Minerais do Brasil: Texto, mapas e SIG. Brasília: CPRM. p. 227-234.

Ferreira, V. P., Sial, A. N., Jardim de Sá, E. F. (1998). Geochemical and isotopic signature of Proterozoic granitoids in terranes of the Borborema structural province, northeastern Brazil. Journal of South America Earth Sciences, 11(5), 439-455. https://doi.org/10.1016/s0895-9811(98)00027-3 
Frost, B. R., Barnes, C. G., Collins, W. J., Arculus, R. J., Ellis, D. J., Frost, C. D. (2001). A geochemical classification for granitic rocks. Journal of Petrology, 42(11), 2033-2048. https://doi.org/10.1093/petrology/42.11.2033

Hackspacher, P. C., Van Schmus, W. R., Dantas, E. L. (1990). Um embasamento transamazônico na Província Borborema. XXXVI Congresso Brasileiro de Geologia, 6, 2661-2677. Anais... Natal: SBG/Núcleo Nordeste.

Hammarstrom, J. M., Zen, E. A. (1986). Aluminum in hornblende: an empirical igneous geobarometer. American Mineralogist, 71(11-12), 1297-1313.

Harris, N. B. W., Pearce, J. A., Tindle, A. G. (1986). Geochemical characteristics of collision-zone magmatism. In: M. P. Coward, A. C. Ries (Eds.), Collision tectonics. Geological Society, Special Publication, 19(1), 67-81. https:// doi.org/10.1144/gsl.sp.1986.019.01.04

Hollanda, M. H. B. M., Archanjo, C. J., Bautista, J. R., Souza, L. C. (2015). Detrital zircon ages and Nd isotope compositions of the Seridó and Lavras da mangabeira Basins (Borborema Province, NE Brazil): Evidence for exhumation and recycling associated with a major shift in sedimentary provenance. Precambrian Research, 258, 186-207. https:// doi.org/10.1016/j.precamres.2014.12.009

Hollanda, M. H. B. M., Archanjo, C. J., Souza, L. C., Dunyi, L., Armstrong, R. (2011). Long-lived Paleoproterozoic granitic magmatism in the Seridó-Jaguaribe domain, Borborema Province-NE Brazil. Journal of South America Earth Sciences, 32(4), 287-300. https://doi.org/10.1016/j.jsames.2011.02.008

Hollanda, M. H. B. M., Souza Neto, J. A., Archanjo, C. J., Stein, H., Maia, A. C. (2017). Age of the granitic magmatism and the W-Mo mineralization in skarns of the Seridó belt (NE Brazil) based on zircon U-Pb (SHRIMP) and molybdenite Re-Os dating. Journal of South American Earth Sciences, 79, 1-11. https://doi.org/10.1016/j.jsames.2017.07.011

Ishihara, S. (1977). The magnetite-series and ilmenite-series granitic rocks. Mining Geology, 27(145), 293-305. https:// doi.org/10.11456/shigenchishitsu1951.27.293

Ishihara, S. (1981). The granitoid series and mineralization. In: B. J. Skinner (Ed.), Seventy-Fifth Anniversary Volume. Economic Geology, 75, p. 458-484. https://doi.org/10.5382/AV75.14

Jardim de Sá, E. F. (1994). A Faixa Seridó (Província Borborema, NE do Brasil) e o seu significado geodinâmico na cadeia Brasiliana/Pan-Africana. Tese (Doutorado). Brasília: Instituto de Geociências - Universidade de Brasília.
Jardim de Sá, E. F., Legrand, J. M., McReath, I. (1981). Estratigrafia de rochas granitóides na região do Seridó (RN-PB), com base em critérios estruturais. Revista Brasileira de Geociências, 11(1), 50-57.

Jardim de Sá, E. F., Macedo, M. H. F., Torres, H. H. F., Kawashita, K. (1988). Geocronology of metaplutonics and the evolution of supracrustal belts in the Borborema Province, NE Brasil. VII Congresso Latino-Americano de Geologia, 49-62. Anais... Belém: SBG/DNPM.

Lameyre, J. (1987). Granites and evolution of the crust. Revista Brasileira de Geociências, 17(4), 349-359.

Legrand, J. M., Deutsch, S., Souza, L. C. (1991). Datação $\mathrm{U} / \mathrm{Pb}$ e granitogênese do Maciço de Acari-RN. XIV Simpósio de Geologia do Nordeste, 12, 172-174. Anais... Recife: SBG.

Li, X. H., Li, Z. X., Li, W. X., Liu, Y., Yuan, C., Wei, G., Qi, C. (2007). U-Pb zircon, geochemical and $\mathrm{Sr}-\mathrm{Nd}-\mathrm{Hf}$ isotopic constraints on age and origin of Jurassic I-and A-type granites from central Guangdong, SE China: a major igneous event in response to foundering of a subducted flatslab? Lithos, 96(1-2), 186-204. https://doi.org/10.1016/j. lithos.2006.09.018

Lopez-Sanchez, M. A., Aleinikoff, J. N., Marcos, A., Martínez, F. J., Llana-Fúnez, S. (2016). An example of low-Th/U zircon overgrowths of magmatic origin in a late orogenic Variscan intrusion: the San Ciprián massif (NW Spain). Journal of the Geological Society, 173(2), 282-291. https:// doi.org/10.1144/jgs2015-071

Luth, W. C., Jahns, R. H., Tuttle, O. F. (1964). The granite system at pressures of 4 to 10 kilobars. Journal of Geophysical Research, 69(4), 759-773. https://doi. org/10.1029/jz069i004p00759

Macêdo Filho, A. A., Souza, Z. S. (2016). Geoquímica do magmatismo Ediacarano Serra do Caramuru, NE da Província Borborema, RN, Brasil. Geologia USP. Série Cientifica, 16(3), 117-142. https://doi.org/10.11606/issn.23169095.v16i3p117-142

Maia, S. M. C. (2004). Estudo integrado geológico/tecnológico de rochas ornamentais: os granitos flores e jacarandá, $R N$. Dissertação (Mestrado). Natal: Universidade Federal do Rio Grande do Norte.

Maniar, P. D., Piccoli, P. M. (1989). Tectonic discrimination of granitoids. Geological Society of America Bulletin, 101(5), 635-643. https://doi.org/10.1130/0016-7606(1989)101 $<0635$ :tdog $>2.3 . c o ; 2$ 
McDonough, W. F., Sun, S. S. (1995). The composition of the Earth. Chemical Geology, 120(3-4), 223-253. https:// doi.org/10.1016/0009-2541(94)00140-4

Medeiros, V. C., Cavalcante, R., Cunha, A. L. C., Costa, A. P., Sá, J. M., Silveira, F. V., Brilhante, J., Silva, M. A., Dantas, A. R. (2017). Magmatismo Ediacarano-Cambriano da Região das mineralizações de W de Currais Novos (RN), Domínio Rio Piranhas-Seridó. XXVII Simpósio de Geologia do Nordeste. Resumos... João Pessoa: SBG.

Medeiros, V. C., Nascimento, M. A. L., Galindo, A. C., Dantas, E. L. (2012). Augen gnaisses riacianos no domínio Rio Piranhas-seridó - Província Borborema, Nordeste do Brasil. Geologia USP. Série Cientifica, 12(2), 3-14. https:// doi.org/10.5327/Z1519-874X2012000200001

Nascimento, M. A. L., Antunes, A. F., Galindo, A. C., Jardim de Sá, E. F., Souza, Z. S. (2000). Geochemical signatures of the Brasiliano-age plutonism in the Serido belt, Northeastern Borborema Province (NE Brazil). Revista Brasileira de Geociências, 30(1), 161-164. https://doi. org/10.25249/0375-7536.2000301161164

Nascimento, M. A. L., Galindo, A. C., de Medeiros, V. C. (2015). Ediacaran to Cambrian magmatic suites in the Rio Grande do Norte domain, extreme Northeastern Borborema Province (NE of Brazil): Current knowledge. Journal of South America Earth Science, 58, 281-299. https://doi. org/10.1016/j.jsames.2014.09.008

Nascimento, M. A. L., Medeiros, V. C., Galindo, A. C. (2008). Magmatismo ediacarano a cambriano no Domínio Rio grande do Norte, Província Borborema, NE do Brasil. Estudos Geológicos, 18(1), 4-25.

Pearce, J. A. (1996). Sources and settings of granitic rocks. Episodes, 19(4), 120-125.

Pearce, J. A., Harris, N. B. W., Tindle, A. G. (1984). Trace elements discrimination diagrams for the tectonic interpretation of granitic rocks. Journal of Petrology, 25(4), 956-983. https://doi.org/10.1093/petrology/25.4.956

Rickwood, P. C. (1989). Boundary lines within petrologic diagrams which use oxides of major and minor elements. Lithos, 22(4), 247-263. https://doi.org/10.1016/0024-4937(89)90028-5

Rogers, J. J. W., Greenberg, J. K. (1981). Trace elements in continental margin magmatism. Part III. Alkali granites and their relationship to cratonization. Geological Society of America Bulletin, 92(1), 6-9. https://doi. org/10.1130/0016-7606(1981)92<6:teicmp >2.0.co;2
Santos, E. J. (1995). O complexo granítico Lagoa das Pedras: acresção e colisão na região de Floresta (Pernambuco), Província Borborema. Tese (Doutorado). São Paulo: Instituto de Geociências - Universidade de São Paulo. https://doi. org/10.11606/T.44.1995.tde-28102015-094036

Santos, E. J. (1999). Programa Levantamentos Geológicos Básicos do Brasil: carta geológica. Belém do São Francisco, Folha SC.24-X-A. Escala 1:250.000. Brasília: CPRM. CD-ROM.

Sato, K., Tassinari, C. C. G., Basei, M. A. S., Siga Júnior, O., Onoe, A. T., De Souza, M. D. (2014). Sensitive High Resolution Ion Microprobe (SHRIMP IIe/MC) of the Institute of Geosciences of the University of São Paulo, Brazil: Analytical method and first results. Geologia USP. Série Científica, 14(3), 3-18. https://doi.org/10.5327/ Z1519-874X201400030001

Sial, A. N. (1987). Granitic rocks in northeast Brazil. $1^{s t}$ International Symposium of Granites Pegmatites, 61-69. Anais... Salvador.

Siégel, C., Bryan, S. E., Allen, C. M., Gust, D. A. (2018). Use and abuse of zircon-based thermometers: A critical review and a recommended approach to identify antecrystic zircons. Earth-Science Reviews, 176, 87-116. https://doi. org/10.1016/j.earscirev.2017.08.011

Silva, M. A. (2016). Magmatismo granítico neoproterozoico no Domínio Rio Piranhas-Seridó: cartografia e petrografia do Pluton Serra da Acauã. Trabalho de Conclusão de Curso (Graduação). Natal: Universidade Federal do Rio Grande do Norte.

Souza, V. O. (2016). Magmatismo granítico na porção central do domínio Rio Piranhas-Seridó, Província Borborema: geologia e petrologia do Stock Flores. Dissertação (Mestrado). Natal: Universidade Federal do Rio Grande do Norte.

Souza, V. O., Galindo, A. C., Alves da Silva, F. C. (2017). O Stock Flores: Exemplo de magmatismo granítico tipo-A no Domínio Rio Piranhas-Seridó, NE da Província Borborema. Pesquisas em Geociências, 44(2), 345-366. https://doi. org/10.22456/1807-9806.78278

Souza, Z. S., Kalsbeek, F., Deng, X. D., Frei, R., Kokfelt, T. F., Dantas, E. L., Li, J. W., Pimentel, M. M., Galindo, A. C. (2016). Generation of continental crust in the northern part of the Borborema Province, northeastern Brazil, from Archaean to Neoproterozoic. Journal of South America Earth Science, 68, 68-96. https://doi.org/10.1016/j. jsames.2015.10.006 
Souza, Z. S., Martin, H., Macedo, M. H. F., Peucat, J. J., Jardim de Sá, E. F. (1993). Un segment de croûte continentale juvénille d'âge protérozoique inférieur: le Complexe de Caicó (Rio Grande do Norte, NE-Brésil). C. R. Académie des Sciences, 316(2), 201-208.

Souza, Z. S., Martin, H., Peucat, J. J., Jardim de Sá, E. F., Macedo, M. H. F. (2007). Calcalkaline magmatism at the Archean-Proterozoic transition: the Caicó complex basement (NE Brazil). Journal of Petrology, 48(11), 2149-2185. https:// doi.org/10.1093/petrology/egm055

Streckeisen, A. L. (1976). To each plutonic rock it's a proper name. Earth-Science Reviews, 12(1), 1-33. https:// doi.org/10.1016/0012-8252(76)90052-0

Takahashi, M., Aramaki, S., Ishihara, S. (1980). Magnetiteseries/ilmenite-series vs. I-type/S-type granitoids. Mining Geology, Special Issue, 8, 13-28.

Thompson, R. N. (1982). Magmatism of the British tertiary volcanic province. Scottish Journal of Geology, 18(1), 49-107. https://doi.org/10.1144/sjg18010049

Tuttle, O. F., Bowen, N. L. (1958). Origin of granite in the light of experimental studies in system $\mathrm{NaAlSi}_{3} \mathrm{O}_{8}-\mathrm{KalSi}_{3} \mathrm{O}_{8}$ $-\mathrm{SiO}_{2}-\mathrm{H}_{2} \mathrm{O}$. Geological Society of America Memoirs, 74, 153. https://doi.org/10.1130/mem74

Van Schmus, W. R., Brito Neves, B. B., Hackspacher, P. C., Babinski, M., Fetter, A. H., Dantas, E. L. (1997). Application of $\mathrm{U}-\mathrm{Pb}$ and $\mathrm{Sm}-\mathrm{Nd}$ geochronology to understanding the geotectonic history of the Borborema Province, NE Brazil and its implications for the evolution of West Gondwana. Extended Abstracts. Campos do Jordão: FAPESP/CNPq CPRM.

Van Schmus, W. R., Brito Neves, B. B., Williams, I. S., Hackspacher, P. C., Fetter, A., Dantas, E. L., Babinski, M. (2003). The Seridó Group of NE Brazil, a late Neoproterozoic pre- to syn-collisional basin in West Gondwana: insights from SHRIMP U-Pb detritial zircon ages and Sm-Nd crustal residence (TDM) ages. Precambrian Research, 127(4), 284-327. https://doi.org/10.1016/s0301-9268(03)00197-9

Watson, E. B., Harrison, T. M. (1983). Zircon saturation revisited: temperature and composition effects in a variety of crustal magma types. Earth and Planetary Science Letters, 64(2), 295-304. https://doi.org/10.1016/0012-821x(83)90211-x
Watson, E. B., Harrison, T. M. (1984). Accessory minerals and the geochemical evolution of crustal magmatic system: a summary and prospectus of experimental approaches. Physics of the Earth and Planetary Interiors, 35(1-3), 19-30. https://doi.org/10.1016/0031-9201(84)90031-1

Whalen, J. B., Currie, K. L., Chappell, B. W. (1987). A-type granites: Geochemical characteristics, discrimination and petrogenesis. Contributions to Mineralogy and Petrology, 95(4), 407-419. https://doi.org/10.1007/bf00402202

Wones, D. R. (1989). Significance of the assemblage titanite + magnetite + quartz in granitic rocks. American Mineralogist, 74(7-8), 744-749.

Wu, F. Y., Jahn, B. M., Wilde, S. A., Lo, C. H., Yui, T. F., Lin, Q., Ge, W., Sun, D. Y. (2003). Highly fractionated I-type granites in NE China (I): geochronology and petrogenesis. Lithos, 66(3-4), 241-273. https://doi.org/10.1016/s0024-4937(02)00222-0

Yang, X. (2017). Lithos Estimation of crystallization pressure of granite intrusions. Lithos, 286-287, 324-329. https://doi. org/10.1016/j.lithos.2017.06.018

Zhang, Y., Yang, J. H., Sun, J. F., Zhang, J. H., Chen, J. Y., Li, X. H. (2015). Petrogenesis of Jurassic fractionated I-type granites in Southeast China: Constraints from wholerock geochemical and zircon $\mathrm{U}-\mathrm{Pb}$ and $\mathrm{Hf}-\mathrm{O}$ isotopes. Journal of Asian Earth Sciences, 111, 268-283. https://doi. org/10.1016/j.jseaes.2015.07.009

Zhou, Z., Ma, C., Xie, C., Wang, L., Liu, Y., Liu, W. (2016). Genesis of highly fractionated I-type granites from Fengshun complex: Implications to tectonic evolutions of South China. Journal of Earth Science, 27(3), 444-460. https:// doi.org/10.1007/s12583-016-0677-3

Zhu, D., Mo, X., Wang, L., Zhao, Z., Niu, Y., Zhou, C., Yang, Y. (2009). Petrogenesis of highly fractionated I-type granites in the Zayu area of eastern Gangdese, Tibet: Constraints from zircon U-Pb geochronology, geochemistry and Sr-Nd-Hf isotopes. Science in China Series D: Earth Sciences, 52(9), 1223-1239. https://doi.org/10.1007/s11430-009-0132-x

Zhu, R. Z., Lai, S. C., Qin, J.F., Zhao, S. W.(2015). Early-Cretaceous highly fractionated I-type granites from the northern Tengchong block, western Yunnan, SW China: Petrogenesis and tectonic implications. Journal of Asian Earth Sciences, 100, 145-163. https://doi.org/10.1016/j.jseaes.2015.01.014 